\title{
Challenges in initiating antiretroviral therapy in 2010
}

\author{
Cécile L Tremblay MD FRCPC ${ }^{1,2}$, Jean-Guy Baril MD ${ }^{3}$, David Fletcher MD FRCPC ${ }^{4}$, Donald Kilby MD ${ }^{5}$, \\ Paul MacPherson PhD MD FRCPC ${ }^{6}$, Stephen D Shafran MD FRCPC ${ }^{7}$, Mark W Tyndall MD SCD FRCPC ${ }^{8}$
}

CL Tremblay, J-G Baril, D Fletcher, et al. Challenges in initiating antiretroviral therapy in 2010. Can J Infect Dis Med Microbiol 2010;21(Suppl C):1-15.

Many clinical trials have shown that initiating antiretroviral therapy (ART) at higher rather than lower CD4 T cell-positive counts results in survival benefit. Early treatment can help prevent end-organ damage associated with HIV replication and can decrease infectivity. The mainstay of treatment is either a non-nucleoside reverse transcriptase inhibitor or a ritonavir-boosted protease inhibitor in combination with two nucleoside reverse transcriptase inhibitors. While effective at combating HIV, ART can produce adverse alterations of lipid parameters, with some studies suggesting a relationship between some antiretroviral agents and cardiovascular disease. As the HIV-positive population ages, issues such as hypertension and diabetes must be taken into account when initiating ART. Adhering to ART can be difficult; however, nonoptimal adherence to ART can result in the development of resistance; thus, drug characteristics and the patient's preparedness to begin therapy must be considered. Reducing the pill burden through the use of fixed-dose antiretroviral drug combinations can facilitate adherence.

\section{Les enjeux relatifs à l'amorce d'un traitement antirétroviral en 2010}

\begin{abstract}
De nombreux essais cliniques ont montré que l'instauration d'un traitement antirétroviral à partir d'un seuil de CD4 T supérieur plutôt qu'inférieur produit un avantage sur la survie. Un traitement précoce peut aider à prévenir l'atteinte des organes cibles associée à la réplication du VIH et réduire l'infectivité. Le traitement repose principalement soit sur un inhibiteur non nucléosidique de la transcriptase inverse, soit sur un inhibiteur de la protéase rehaussé par ritonavir en association avec deux inhibiteurs nucléosidiques de la transcriptase inverse. Bien qu'efficaces pour combattre le $\mathrm{VIH}$, les antirétroviraux peuvent avoir une influence négative sur les paramètres lipidiques, des études ayant fait état d'un lien entre certains antirétroviraux et la maladie cardiovasculaire. À mesure que la population VIH-positive vieillit, il faut tenir compte de problèmes comme l'hypertension et le diabète au moment d'amorcer des antirétroviraux. La fidélité aux antirétroviraux pose parfois problème. Toutefois, une piètre observance thérapeutique peut contribuer à la résistance. Il faut donc prendre en compte les caractéristiques des patients et leur volonté de démarrer le traitement. On peut réduire le nombre de comprimés en utilisant des antirétroviraux d'association à dose fixe afin de promouvoir l'observance thérapeutique.
\end{abstract}

Key Words: Antiretroviral therapy; CD4 cell count; Complications of treatment; HIV infection; Patient readiness; When to start treatment

$\mathrm{T}$ he objective of the present article is to review the most recent HIV treatment data and discuss various aspects of major consensus guidelines. There are many factors that confound the treatment of the nonpregnant adult, and these are addressed in a series of patient vignettes. The major issues to be discussed are when to start treatment, lifelong treatment considerations and the factors that further complicate treatment decisions. The focus of the current article will be the types of decisions that must be made when initiating therapy - or even earlier - with the view that treatment will be continued long term, which provides the setting for the patient to develop concomitant illnesses.

The complex issues that surround lifelong treatment with antiretroviral therapy (ART) have not been addressed by randomized clinical trials, but have been examined in retrospective chart reviews, cohort studies and similar investigations. Thus, using these studies as a basis for clinical decision making becomes more difficult. We will attempt to put some of these studies into perspective and try to derive action plans for the patient vignettes we present. The current document is not intended to replace the guidelines produced by several credible organizations, notably, the BC Centre for Excellence in HIV/AIDS (1), the European AIDS

Clinical Society (EACS) (2), the International AIDS Society USA (3), The United States Department of Health and Human Services (DHHS) (4) and the Quebec Comité consultatif sur la prise en en charge des personnes vivant avec le VIH (5). While there are broad similarities among these guidelines, there are also differences, reflecting the nondefinitive nature of some of the data and the use of opinion in developing recommendations. We will discuss some areas in which these guidelines diverge.

\section{Early versus deferred treatment}

\section{WHEN TO START ART}

The question of when to start treatment arises largely due to the long-term toxicity and cost of HIV treatments. Given this, the time to optimally begin ART in nonpregnant adults in terms of CD4 T cell-positive $\left(\mathrm{CD}^{+}\right)$counts has vacillated over the years, but it appears that emerging data are finally beginning to suggest an optimal starting point. Several studies now show that initiating $\mathrm{ART}$ at a $\mathrm{CD}^{+}{ }^{+}$count of no less than 350 cells/ $\mu \mathrm{L}$ improves survival versus initiating treatment at lower $\mathrm{CD}^{+}{ }^{+}$counts. Although most of the data were generated by cohort studies, one randomized trial supports earlier treatment (at no less than $200 \mathrm{CD} 4^{+}$cells $/ \mu \mathrm{L}$ ).

${ }^{1}$ Division of Infectious Diseases, Centre Hospitalier de L'Université de Montréal-Hotel Dieu; ${ }^{2}$ Department of Microbiology and Immunology,

University of Montreal; ${ }^{3}$ Clinique du Quartier Latin and Centre Hospitalier de l'Université de Montréal, Montréal, Québec; ${ }^{4}$ Maple Leaf

Medical Clinic, Toronto; ${ }^{5}$ University of Ottawa; ${ }^{6}$ Ottawa Health Research Institute; Department of Biochemistry, Microbiology and

Immunology, University of Ottawa, Division of Infectious Diseases, Ottawa Hospital General Campus, Ottawa, Ontario; ${ }^{7}$ Division of

Infectious Diseases, University of Alberta, Edmonton, Alberta; ${ }^{8}$ Division of Infectious Diseases, University of British Columbia, BC Centre for

Excellence in HIVIAIDS, St Paul's Hospital, Vancouver, British Columbia

Correspondence: Dr Cécile L Tremblay, Département de microbiologie et immunologie, Pavillon Roger-Gaudry, Université de Montréal, CP 6128,

Succursale Centre-ville, Montréal, Québec H3C 3J7. Telephone 514-343-6111 ext 51736, fax 514-343-5701,

e-mail tremblay@umontreal.ca

Received for publication March 23, 2010. Accepted July 6, 2010 
TABLE 1

Baseline parameters in The North American AIDS Cohort Collaboration on Research and Design (6)

\begin{tabular}{lcccc}
\hline & \multicolumn{2}{c}{ CD4 $^{+}$count stratum (cells/ $\mathbf{\mu L}$ ) } \\
\cline { 2 - 5 } & \multicolumn{2}{c}{$\mathbf{3 5 0 - 5 0 0}$} & \multicolumn{2}{c}{$>\mathbf{5 0 0}$} \\
\cline { 2 - 5 } & \multicolumn{2}{c}{ Treatment } & \multicolumn{2}{c}{ Treatment } \\
\cline { 2 - 5 } & Early & Deferred & Early & Deferred \\
\hline CD4 $^{+}$count, cells $/ \mu \mathrm{L}$ & 422 & 431 & 679 & 664 \\
Viral load, $\log _{10}$ copies $/ \mathrm{mL}$ & 4.2 & 4.1 & 3.5 & 3.7 \\
\hline
\end{tabular}

CD4 $4^{+}$CD4-positive T cell

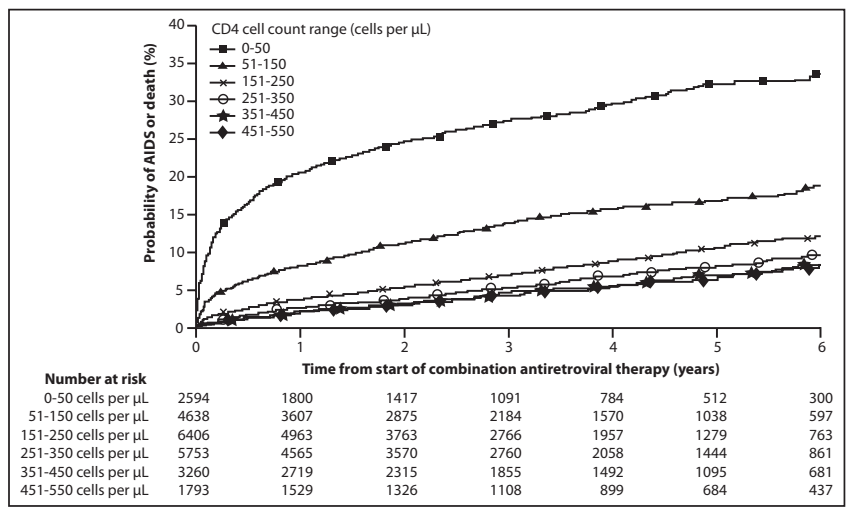

Figure 1) Cumulative probability of AIDS or death after initiation of combination antiretroviral therapy, according to range of CD4positive $T$ cell count at the time of treatment initiation. Adapted from reference 8

The North American AIDS Cohort Collaboration on Research and Design (NA-ACCORD) studied the effects of early versus deferred treatment in treatment-naive patients who had not yet experienced an AIDS-defining illness. More than 17,000 patients were stratified into two groups: one with a $\mathrm{CD}^{+}{ }^{+}$count of 350 cells $/ \mu \mathrm{L}$ to 500 cells $/ \mu \mathrm{L}$, and a group with a CD4 ${ }^{+}$count of more than 500 cells $/ \mu \mathrm{L}$. The early treatment group consisted of patients who received treatment while they were within one of the two ranges. The deferredtreatment group received treatment only after their $\mathrm{CD}^{+}$count fell below that of their original stratified group (ie, below $350 \mathrm{cells} / \mathrm{\mu L}$ or below 500 cells $/ \mu \mathrm{L}$ ). The median baseline $\mathrm{CD}^{+}$counts and viral loads are shown in Table 1 . In both groups, approximately $25 \%$ of patients received early treatment while $75 \%$ received deferred treatment. Importantly, in patients with baseline $\mathrm{CD}^{+}$counts in the lower stratum, the death rate was $69 \%$ higher in patients who deferred treatment than in patients who received treatment while their $\mathrm{CD}^{+}$ count was still within their original stratum. The results were even more dramatic for patients beginning in the greater than $500 \mathrm{cells} / \mathrm{\mu L}$ stratum, in which the death rate was $94 \%$ higher for delayed treatment versus early treatment $(6,7)$. Baseline viral load had no impact on this analysis, but it is important to note that in this type of observational cohort study, the characteristics of patients starting or deferring treatment could be very different. For example, in the early therapy group, there were fewer injection drug users (IDUs) and, therefore, fewer with hepatitis $\mathrm{C}$ virus (HCV) coinfection (6).

The Antiretroviral Cohort Collaboration (ART-CC) group (8) examined treatment-naive patients with $\mathrm{CD}^{+}{ }^{+}$counts of less than 550 cells $/ \mu \mathrm{L}$ and no AIDS-defining events. The study compared the risk of death alone or a composite of AIDS and death in patients with $\mathrm{CD}^{+}$counts in adjacent ranges of 100 cells/ $\mu \mathrm{L}$, with these ranges increasing in increments of 25 cells $/ \mu \mathrm{L}$ - that is, 0 cells $/ \mu \mathrm{L}$ to 100 cells $/ \mu \mathrm{L}$ versus $101 \mathrm{cells} / \mu \mathrm{L}$ to $200 \mathrm{cells} / \mu \mathrm{L} ; 26 \mathrm{cells} / \mu \mathrm{L}$ to

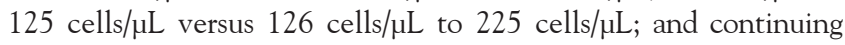
until 351 cells $/ \mu \mathrm{L}$ to 450 cells $/ \mu \mathrm{L}$ versus 451 cells $/ \mu \mathrm{L}$ to 550 cells $/ \mu \mathrm{L}$.
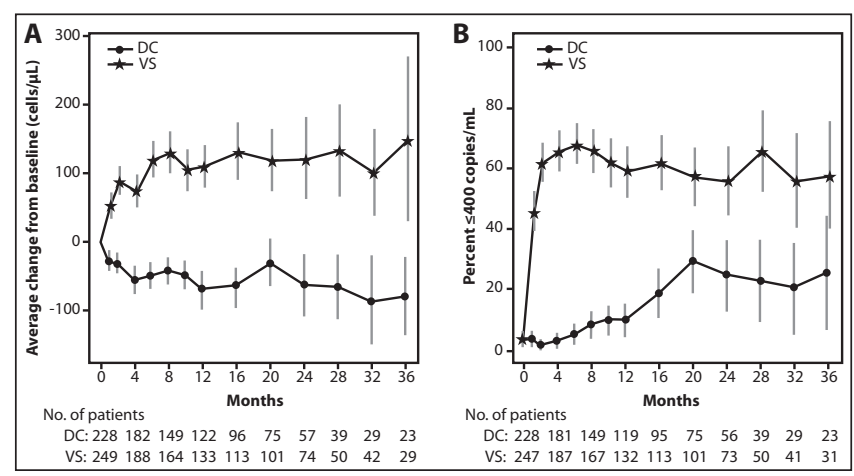

Figure 2) Mean change from baseline CD4-positive $T$ cell count (A) and percentage of patients with plasma HIV RNA levels $\leq 400$ copies/mL (B) during follow-up. DC Drug conservation; No Number; VS Viral suppression. Vertical bars represent 2 standard errors. Adapted from reference 9

There was a $28 \%$ increase in the risk of AIDS or death in the group that started combination treatment at $\mathrm{CD} 4^{+}$counts in the 251 cells $/ \mu \mathrm{L}$ to 350 cell $/ \mu \mathrm{L}$ range versus those that started at 351 cells $/ \mu \mathrm{L}$ to 450 cells $/ \mu \mathrm{L}$ (Figure 1 ). Similarly, the risk of death alone was $13 \%$ higher in the lower $\mathrm{CD}^{+}$stratum than in the higher stratum. There appeared to be no benefit to starting treatment earlier in the $\mathrm{CD}^{+}{ }^{+}$strata above 450 cells/ $\mu \mathrm{L}$. The authors concluded that ART should be started at no less than $350 \mathrm{CD} 4^{+} / \mu \mathrm{L}$.

Further support for early treatment comes from the Strategies for Management of Anti-Retroviral Therapy (SMART) (9) study, originally designed to examine $\mathrm{CD} 4^{+}$count-based structured treatment interruption versus continuous ART. In this study, patients with baseline $\mathrm{CD}^{+}$counts of more than 350 cells $/ \mu \mathrm{L}$ were randomly assigned to either immediate treatment or delayed treatment

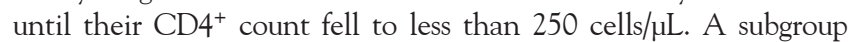
analysis of patients who were ART naive or who had not received ART for at least six months reported a median baseline $\mathrm{CD} 4^{+}$count of 447 cells $/ \mu \mathrm{L}$ and a median viral load of $4.5 \log _{10}$ copies $/ \mathrm{mL}$. In effect,

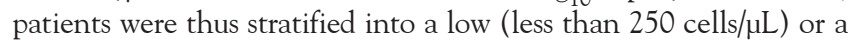
high (more than 350 cells $/ \mu \mathrm{L}$ ) $\mathrm{CD}^{+}{ }^{+}$stratum when starting treatment. Patients treated in the higher $\mathrm{CD}^{+}{ }^{+}$stratum had one-fifth the rate of opportunistic disease and death than those in the lower $\mathrm{CD}^{+}$stratum (Figure 2) $(9,10)$.

One of the few randomized trials to investigate early versus standard timing of therapy was the open-label Comprehensive International Program of Research on AIDS (CIPRA HT001) (11) study in patients with median $\mathrm{CD}^{+}$counts between 200 cells $/ \mu \mathrm{L}$ and 350 cells/ $\mu \mathrm{L}$ and no previous AIDS-defining illness. The early group initiated treatment with zidovudine, lamivudine and efavirenz within two weeks of enrollment, while the other group started therapy with the same regimen when their $\mathrm{CD} 4^{+}$counts fell to 200 cells $/ \mu \mathrm{L}$ or lower, or if they developed an AIDS-defining illness. There was a significant reduction in both the risk of death and of developing tuberculosis in the early treatment group. In addition, there was a significant reduction in zidovudine-related anemia in the early treatment group.

Viral load may not be a good predictor for determining the rate of $\mathrm{CD}^{+}{ }^{+}$depletion. Investigating HIV-infected, untreated patients, Rodriguez et al (12) divided subjects into five viral load strata (copies of plasma HIV-RNA/mL): less than 500; 501 to 2000; 2001 to 10,$000 ; 10,001$ to 40,000 ; and more than 40,000. Fitting a regression of yearly $\mathrm{CD}^{+}$cell loss yielded a small coefficient of determination of 0.01 , indicating that only a portion of the drop in $\mathrm{CD}^{+}$counts was attributable to viral load at presentation. This 
supports the results of previously discussed studies in determining the time to optimally begin ART based on $\mathrm{CD}^{+}$counts.

\section{Immune activation and inflammation}

Benefits of earlier treatment are not just reflected in increased CD4 ${ }^{+}$ counts or decreased viral loads. Early treatment may decrease the inflammation and immune activation that is responsible for the higher rates of end-organ damage seen in HIV-positive patients. In fact, HIV-infected patients have higher levels of inflammatory markers than noninfected individuals; the presence of these markers predicts the development of non-AIDS clinical events. This is supported by evidence from the SMART study, showing that patients undergoing structured treatment interruption had significantly higher all-cause mortality than patients who received continuous ART, with most of the excess mortality due to non-AIDS causes; only $8 \%$ of deaths were due to opportunistic disease $(13,14)$.

Related to the increased mortality in the SMART study were increased levels of the inflammatory marker interleukin-6 (IL-6) and the coagulation/fibrinolysis marker D-dimer (a fibrin degradation product). Rodger et al (13) examined high-sensitivity C-reactive protein (hsCRP), amyloid A, amyloid P, IL-6, D-dimer and prothrombin fragment $1+2$ to investigate whether these markers could predict the risk of a patient developing opportunistic disease. The results indicated that increased hsCRP and IL-6 were, in fact, independent predictors for the occurrence of an opportunistic event.

Neuhaus and Jacobs (14) compared study entry levels of hsCRP, IL-6, D-dimer and cystatin-C (a marker of kidney function) for SMART participants with aged-matched participants in the large general population-based Multi-Ethnic Study of Atherosclerosis (MESA) (15) and the Coronary Artery Risk Development In Young Adults (CARDIA) study (16). SMART patients had higher levels of all four markers even after adjustment for cardiovascular (CV) risk factors regardless of which SMART treatment group they belonged to (14).

Immune reconstitution inflammatory syndrome can complicate the initiation of ART, mainly in patients starting ART with $\mathrm{CD}^{+}$ counts of below 100 cells $/ \mu \mathrm{L}$. The AIDS Clinical Trials Group Study (ACTG) A5164 (17) randomly assigned patients with opportunistic infections (excluding tuberculosis) to ART at study entry or at 28 or more days from entry. Each decrement of $10 \mathrm{CD} 4^{+} / \mu \mathrm{L}$ resulted in a significant $20 \%$ or $30 \%$ increase in the risk of death (multivariate and univariate analysis, respectively). Once again, this gives further support to treatment when $\mathrm{CD}^{+}$counts are higher rather than lower.

\section{Excess non-AIDS events}

Another argument in favour of early treatment is its potential benefit on non-AIDS events. This is critical because non-AIDS events cause far more morbidity and mortality in patients receiving combination ART than AIDS events. Non-AIDS death rates were positively related to low $\mathrm{CD} 4^{+}$counts and high viral loads (18). This relationship persisted for non-AIDS events such as liver disease, renal disease and non-AIDS malignancies. The etiology of this relationship is possibly attributable to complications of chronic immune activation and increased T cell turnover (18). Justice et al (18) also reported that the routine clinical biomarkers of anemia (as measured by hemoglobin), liver injury (as measured by patient age, aspartate aminotransferase, alanine aminotransferase and platelet levels), renal injury (as measured by estimated glomerular filtration rate [eGFR]), and chronic viral hepatitis, were able to differentiate mortality risk.

Many potentially modifiable risk factors for death in HIVinfected patients were identified by the Data Collection on Adverse
Events of Anti-HIV Drugs (D:A:D) trial (19). These included smoking, low body mass index, hypertension, diabetes, hepatitis $\mathrm{B}$ virus (HBV)/HCV coinfection, low $\mathrm{CD}^{+}{ }^{+}$count and higher viral load. The risk of death due to any of these causes was greater in patients with lower $\mathrm{CD}^{+}$counts. Every $50 \mathrm{CD}^{+}$count increase reduced the overall risk of death by $16 \%$ (20).

\section{ART and HIV transmission}

There are several lines of evidence to suggest that suppression of HIV can reduce transmission. Decreased plasma viral load is associated with decreased viral load in genital secretions, and there is a direct correlation between viral load and probability of sexual transmission (21) and vertical transmission (22-25). A systematic review (26) of 5021 heterosexual couples and 461 HIV transmission events found that there were no cases of transmission from an infected partner who was receiving ART and had a plasma viral load of below 400 copies/mL.

It is important to keep in mind, however, that these data come from observational, uncontrolled, noninterventional studies and, thus, it remains unclear to what extent ART reduces transmission. Clinicians and patients should also bear in mind that there have been many controlled studies (27-34) demonstrating shedding of HIV in the genital secretions of individuals receiving ART who had undetectable viral loads in blood plasma.

In a phylogenetic analysis, Brenner et al (35) showed that almost one-half $(49 \%)$ of onward HIV transmissions were due to primary HIV infection, and that viral loads were significantly higher in primary HIV infection and untreated chronically infected patients than in treated, chronically infected patients. Similar results were found by Fisher et al (36) in the United Kingdom, who also showed that HIV transmission was associated with recent HIV infection, higher viral load, younger age and concomitant sexually transmitted infections.

\section{Willingness to start treatment}

The critical factor in initiating ART is the readiness of the patient to make the commitment to adhere to the regimen in view of the lifelong duration of therapy and the adverse events that may occur. Balfour et al (37) conducted a randomized controlled trial of a four-week psychoeducational adherence intervention versus standard HIV clinic multidisciplinary team care. Psychological readiness to begin ART was measured by the 10 -item HIV Medication Readiness Scale. Four weeks after the start of the study, patients in the intervention group showed significantly greater medication readiness scores than those in the standard arm of the study. One of the key factors that can affect readiness is depression, which should be addressed in patients before initiating highly active ART. In this study, depressed patients who received the intervention had significantly lower depression scores after four weeks than patients in the standard arm.

Balfour et al (38) demonstrated that the HIV Medication Readiness Scale is able to differentiate between patients who will be optimally adherent versus those who will be suboptimally adherent to therapy, with high internal consistency (alpha = $0.90)$, test-retest reliability $(\mathrm{r}=0.83)$ and sensitivity to change following the four-session psychoeducational intervention described above. Such scales may then provide the opportunity to intervene earlier to enhance adherence to antiretroviral medications.

\section{GUIDELINES}

Guidelines are unanimous in recommending treatment for symptomatic patients and for asymptomatic patients with $\mathrm{CD}^{+}$counts 


\section{TABLE 2}

\section{Summary of recent antiretroviral therapy studies in} treatment-naive patients

\begin{tabular}{|c|c|c|c|c|}
\hline Study (ref) & Treatment & Vs & Treatment & In addition to... \\
\hline \multicolumn{5}{|c|}{ Non-nucleoside reverse transcriptase inhibitor (NNRTI) study } \\
\hline $2 \mathrm{NN}(40)$ & Efavirenz & & Nevirapine & $\begin{array}{l}\text { Stavudine/ } \\
\text { lamivudine }\end{array}$ \\
\hline \multicolumn{5}{|c|}{ Protease inhibitor studies } \\
\hline $\begin{array}{l}\text { CASTLE } \\
(43)\end{array}$ & $\begin{array}{c}\text { Atazanavir/ } \\
\text { ritonavir }\end{array}$ & & $\begin{array}{l}\text { Lopinavir/ } \\
\text { ritonavir }\end{array}$ & $\begin{array}{c}\text { Tenofovir/ } \\
\text { emtricitabine }\end{array}$ \\
\hline $\begin{array}{l}\text { ARTEMIS } \\
(45)\end{array}$ & $\begin{array}{l}\text { Darunavir/ } \\
\text { ritonavir }\end{array}$ & & $\begin{array}{l}\text { Lopinavir/ } \\
\text { ritonavir }\end{array}$ & $\begin{array}{c}\text { Tenofovir/ } \\
\text { emtricitabine }\end{array}$ \\
\hline KLEAN (47) & $\begin{array}{c}\text { Fosamprenavir/ } \\
\text { ritonavir }\end{array}$ & & $\begin{array}{l}\text { Lopinavir/ } \\
\text { ritonavir }\end{array}$ & $\begin{array}{l}\text { Abacavir/ } \\
\text { lamivudine }\end{array}$ \\
\hline Gemini (49) & $\begin{array}{l}\text { Saquinavir/ } \\
\text { ritonavir }\end{array}$ & & $\begin{array}{l}\text { Lopinavir/ } \\
\text { ritonavir }\end{array}$ & $\begin{array}{c}\text { Tenofovir/ } \\
\text { emtricitabine }\end{array}$ \\
\hline ALERT (50) & $\begin{array}{c}\text { Fosamprenavir/ } \\
\text { ritonavir }\end{array}$ & & $\begin{array}{c}\text { Atazanavir/ } \\
\text { ritonavir }\end{array}$ & $\begin{array}{c}\text { Tenofovir/ } \\
\text { emtricitabine }\end{array}$ \\
\hline \multicolumn{5}{|c|}{ Protease inhibitor versus NNRTI study } \\
\hline $\begin{array}{l}\text { ACTG A5142 } \\
(52)^{*}\end{array}$ & Efavirenz & & $\begin{array}{l}\text { Lopinavir/ } \\
\text { ritonavir }\end{array}$ & $\begin{array}{l}\text { Lamivudine plus one of the } \\
\text { following: zidovudine, } \\
\text { stavudine or tenofovir }\end{array}$ \\
\hline \multicolumn{5}{|c|}{ Integrase inhibitor studies } \\
\hline $\begin{array}{l}\text { STARTMRK } \\
(57)\end{array}$ & Raltegravir & & Efavirenz & $\begin{array}{c}\text { Tenofovir/ } \\
\text { emtricitabine }\end{array}$ \\
\hline $004(58)$ & Raltegravir & & Efavirenz & $\begin{array}{l}\text { Tenofovir/ } \\
\text { lamivudine }\end{array}$ \\
\hline \multicolumn{5}{|c|}{ Nucleoside reverse transcriptase inhibitor studies } \\
\hline $\begin{array}{l}\text { ACTG } 5202 \\
(55)\end{array}$ & $\begin{array}{l}\text { Abacavir/ } \\
\text { lamivudine }\end{array}$ & & $\begin{array}{c}\text { Tenofovir/ } \\
\text { emtricitabine }\end{array}$ & $\begin{array}{c}\text { Efavirenz or } \\
\text { atazanavir/ritonavir }\end{array}$ \\
\hline $\begin{array}{l}\text { ASSERT } \\
(60)\end{array}$ & $\begin{array}{l}\text { Abacavir/ } \\
\text { lamivudine }\end{array}$ & & $\begin{array}{c}\text { Tenofovir/ } \\
\text { emtricitabine }\end{array}$ & Efavirenz \\
\hline HEAT (61) & $\begin{array}{l}\text { Abacavir/ } \\
\text { lamivudine }\end{array}$ & & $\begin{array}{c}\text { Tenofovir/ } \\
\text { emtricitabine }\end{array}$ & Lopinavir/ritonavir \\
\hline $\begin{array}{c}\text { ABCDE } \\
(102)\end{array}$ & Abacavir & & Stavudine & $\begin{array}{l}\text { Lamivudine/ } \\
\text { efavirenz }\end{array}$ \\
\hline
\end{tabular}

*Study ACTG A5142 also included a nucleoside reverse transcriptase inhibitorsparing arm consisting of efavirenz and lopinavir. ref Reference; Vs Versus

of less than 350 cells $/ \mu L$. For the most part, guidelines support treating at $\mathrm{CD}^{+}$counts above 350 cells $/ \mu \mathrm{L}$ if the patient is coinfected with HBV or HCV, or has end-organ damage. Only the DHHS recommends treating uniformly at this $\mathrm{CD}^{+}$count, but the panel was not unanimous. Similarly, the DHHS recommends treating at $\mathrm{CD}^{+}{ }^{+}$counts above 500 cells/ $\mu \mathrm{L}$ but, again, the panel was not unanimous on this issue (1-5).

\section{Capsule}

- Studies show that treating at higher $\mathrm{CD}^{+}$counts improves survival.

- Early treatment can decrease the inflammation and immune activation that is responsible for end-organ damage in HIVinfected individuals.

- Non-AIDS events are a more significant cause of mortality in patients receiving ART than are AIDS events.

- Viral suppression can reduce transmission.

- The patient should be assessed for willingness to start treatment.

\section{Available therapeutic options}

Before initiating therapy, several issues must be considered aside from drug efficacy. Genotypic testing should be performed because
$7 \%$ of treatment-naive Canadian HIV patients harbour major primary drug resistance mutations (39). Issues to be considered for the female patient are child-bearing potential and knowledge about and access to effective contraception. Great consideration must be given to tolerability because bothersome adverse events can impede adherence to therapeutic regimens. Gastrointestinal symptoms and lipid abnormalities appear to be generally associated with protease inhibitor (PI)-based regimens, while rash and central nervous system adverse effects are more associated with efavirenz-based regimens. Hepatic aminotransferase level elevations have been associated with both types of regimens (4). It must be determined which adverse events the patient is able or willing to tolerate.

The discussion that follows includes a brief description of the key studies that led to current recommendations and a comparison of current recommendations. Table 2 lists the studies to be discussed, along with the comparative agents that were investigated.

\section{Non-nucleoside reverse transcriptase inhibitors}

The 2NN study (40) in treatment-naive patients compared efavirenz with once- or twice-daily nevirapine, both in addition to stavudine plus lamivudine. The median baseline CD4 ${ }^{+}$ count was approximately 190 cells/ $\mu \mathrm{L}$, and the median baseline viral load was $4.7 \log _{10}$ copies/mL of HIV-RNA. Although there was no significant difference in efficacy between the two nonnucleoside reverse transcriptase inhibitors (NNRTIs) the outcome failed to show that nevirapine was noninferior to efavirenz $(4,40)$. Efavirenz was significantly better tolerated than oncedaily nevirapine.

It has also been reported that hypersensitivity reactions and hepatotoxicity occur more frequently with nevirapine in patients with higher $\mathrm{CD}^{+}{ }^{+}$counts. In women and men with baseline $\mathrm{CD} 4^{+}$counts of less than 250 cells $/ \mu \mathrm{L}$ and less than 400 cells/ $\mu \mathrm{L}$, respectively, nevirapine can be used as an alternative to efavirenz (4).

Due to teratogenicity shown in nonhuman primates (4), efavirenz is not recommended for women of child-bearing potential who are trying to have children or are sexually active but not using highly effective contraception. However, the Antiretroviral Pregnancy Registry (41) has not identified a clear signal for human teratogenicity.

Central nervous system effects have been reported to occur within the first few doses of efavirenz administration. These can include drowsiness, somnolence, insomnia, abnormal dreams, dizziness, impaired concentration and attention span, depression, hallucination, exacerbation of psychiatric disorders, psychosis and suicidal ideation. Patients with a history of psychiatric illness or injection drug use and patients using concomitant medications with neuropsychiatric effects are at greater risk. The symptoms usually taper or clear within one month (4).

There is a high degree of cross-resistance between efavirenz and nevirapine. Etravirine - commonly considered to be a secondgeneration NNRTI - is active against some HIV strains that are resistant to these NNRTIs but not against all (4). The absence of data regarding etravirine in this population combined with its pill burden does not support the use of this agent in treatment-naive patients.

PIs

After it was realized that boosting with ritonavir $(r)$ increased the effectiveness of PIs, co-administered lopinavir/ $\mathrm{r}$ came into widespread use. Many further studies established several additional boosted PI options. Because lopinavir/r was, at one point, the only preferred PI in the DHHS guidelines (4), clinical trials of comparative PIs were usually conducted against this combination. However, lopinavir/ $\mathrm{r}$ is no longer a preferred regimen in the DHHS guidelines 
due to the dosage of its $r$ component, to be discussed later in the present article, and the observation that it is associated with an increased risk of myocardial infarction (MI) in the D:A:D study (42). However, lopinavir/ $\mathrm{r}$ is still considered a preferred option in other guidelines, including British Columbia, EACS and Quebec $(1,2,5)$.

The Combination with Tenofovir-Emtricitabine versus Lopinavir/Ritonavir in Combination with Tenofovir-Emtricitabine to Assess Safety and Efficacy (CASTLE) study (43) was an openlabel, noninferiority trial that compared atazanavir/ $\mathrm{r}$ with lopinavir/r each in combination with tenofovir/emtricitabine. The median baseline viral load was $4.98 \log _{10}$ copies/mL and median baseline $\mathrm{CD}^{+}{ }^{+}$count was 205 cells/ $\mu \mathrm{L}$. After 48 weeks, the regimens showed similar achievement of viral load to less than 50 copies $/ \mathrm{mL}$ and increased $\mathrm{CD}^{+}$count. Follow-up data at 96 weeks continued to show noninferiority; however, an intent-totreat analysis (44) showed a significantly higher response rate for atazanavir/r due to the higher discontinuation rate in the lopinavir $/ \mathrm{r}$ arm. Indeed, atazanavir/r showed less gastrointestinal toxicity than lopinavir/r but more hyperbilirubinemia.

The randomized, open-label AntiRetroviral Therapy with TMC114 ExaMined In naive Subjects (ARTEMIS) study (45) compared darunavir/ $\mathrm{r}$ with lopinavir/ $\mathrm{r}$, along with tenofovir/emtricitabine. The median baseline viral loads were $4.86 \log _{10}$ copies $/ \mathrm{mL}$ and $4.84 \log _{10}$ copies $/ \mathrm{mL}$, respectively, with median baseline CD4 ${ }^{+}$

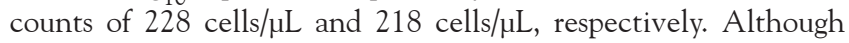
ARTEMIS was a noninferiority trial, after 96 weeks, a higher proportion of patients taking darunavir/ $\mathrm{r}$ achieved a viral load of below 50 copies $/ \mathrm{mL}$. This difference was maintained in the subgroup of patients who had a viral load of greater than 100,000 copies/mL and in the subgroup of patients with $\mathrm{CD}^{+}$counts of less than 200 cells/ $\mu \mathrm{L}$. However, this difference did not persist in the subgroup of patients with viral loads of less than 100,000 copies $/ \mathrm{mL}$ or in the subgroup of patients with $\mathrm{CD}^{+}$counts of at least 200 cells/ $\mu \mathrm{L}$. Overall, both regimens had a similar effect on improving $\mathrm{CD}^{+}$ counts. Fewer darunavir/r patients discontinued treatment due to adverse events, with significantly less diarrhea in this group.

Nelson et al (46) further analyzed the 96-week ARTEMIS results and determined that the superior virological results of darunavir/r held when adjusting for baseline predictors of response such as adherence, age, race and baseline HIV-1 RNA levels, or when adjusting for the higher lopinavir/r dropout rate.

The open-label, noninferiority Kaletra versus Lexiva with Epivir and Abacavir in ART-Naive patients (KLEAN) study (47) compared fosamprenavir/ $\mathrm{r}$ with lopinavir/r, both given with abacavir/ lamivudine. The median baseline viral load was $5.1 \log _{10}$ copies $/ \mathrm{mL}$,

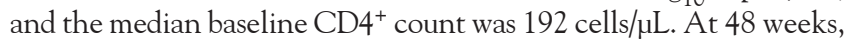
fosamprenavir/r was noninferior to lopinavir/ $\mathrm{r}$ for the percentage of patients with viral loads of less than 400 copies $/ \mathrm{mL}$ and less than 50 copies $/ \mathrm{mL}$. These results did not appear to vary based on initial viral load (less than 100,000 copies/mL or 100,000 copies/mL or greater). Improvements in $\mathrm{CD}^{+}$counts appear similar with the two regimens (47). Pulido et al (48) reported on the 144-week results of the KLEAN study. Although the results seemed to indicate that the two regimens were similar, the study extension was not adequately powered to test for noninferiority. Tolerability was similar for both regimens.

The open-label, noninferiority Gemini (49) study investigated saquinavir/r versus lopinavir/r, each in combination with tenofovir/emtricitabine. The mean baseline viral load was $5.18 \log _{10}$ copies of HIV-RNA/mL, and the median baseline $\mathrm{CD}^{+}$count was 142 cells $/ \mu \mathrm{L}$. At week 48, saquinavir/ $\mathrm{r}$ was noninferior to lopinavir/ $\mathrm{r}$ in the proportion of patients with viral loads of less than 400 copies $/ \mathrm{mL}$ and less than 50 copies $/ \mathrm{mL}$. There was no significant difference between the two groups with respect to the change in $\mathrm{CD}^{+}$count. The regimens were equally well tolerated.

The Atazanavir or Lexiva With Ritonavir and Truvada (ALERT) trial (50) compared fosamprenavir once daily with atazanavir once daily, each boosted by $\mathrm{r} 100 \mathrm{mg}$ once daily, both in combination with tenofovir/emtricitabine. Although the atazanavir regimen has been well studied and is an approved regimen, this fosamprenavir regimen was investigational, using a lower than the currently approved $\mathrm{r}$ dosage (200 $\mathrm{mg}$ daily). The median baseline viral load was $4.9 \log _{10}$ copies $/ \mathrm{mL}$ and baseline $\mathrm{CD}^{+}$count was 171 cells $/ \mu \mathrm{L}$. In both regimens, similar proportions of patients achieved viral loads of less than 50 copies $/ \mathrm{mL}$, with similar $\mathrm{CD}^{+}$ increases. Fewer fosamprenavir/ $\mathrm{r}$ patients reported moderate to severe adverse events due to the occurrence of hyperbilirubinemia in the atazanavir/ $\mathrm{r}$ arm of the trial.

There is some cross-resistance among the various PIs, which increases with the accumulation of multiple mutations. Both tipranavir and darunavir are active against many of these cross-resistant strains of HIV (4).

\section{Choice of NNRTI versus PI}

The issue of whether to start an HIV-infected patient with an NNRTI or PI in combination with two nucleoside reverse transcriptase inhibitors (NRTIs) has never been clearly resolved; selection is based mainly on anticipated adverse events and pill burden.

A major study in this area is the open-label, 112-week ACTG A5142 study (51), which compared efavirenz with lopinavir/r, each in combination with two NRTIs, lamivudine plus one of zidovudine, stavudine or tenofovir. There was a third NRTIsparing arm consisting of efavirenz plus lopinavir/r, but this arm has been largely discounted due to toxicity. The median baseline viral load was $4.8 \log _{10}$ copies $/ \mathrm{mL}$ and the median baseline

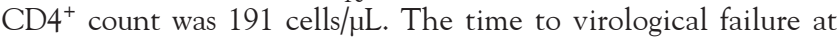
112 weeks, the percentage of patients with viral loads of less than 200 copies $/ \mathrm{mL}$ at 96 weeks and the percentage of patients with viral loads of less than 50 copies/mL at 96 weeks were significantly greater for efavirenz than for lopinavir/r. In patients with a baseline viral load of 100,000 copies $/ \mathrm{mL}$ or more, time to virological failure was greater for efavirenz than for lopinavir/r; but in patients with viral loads of less than 100,000 copies/mL the time to virological failure was similar in the two groups. However, the increase in $\mathrm{CD}^{+}{ }^{+}$count was greater for lopinavir/ $\mathrm{r}$ at week 96 , but similar in the two groups at week 48. Significantly more rash was reported in the efavirenz arm and significantly more diarrhea occurred in the lopinavir/r arm; however, the time to discontinuation was similar in the two groups.

Haubrich et al (52) also compared the development of resistance at virological failure and, although as stated above, virological failure was less frequent with efavirenz, resistance at failure was more frequent with this regimen.

The Atazanavir, Ritonavir, Tenofovir, Emtricitabine and Nevirapine (ArTEN) study (53) compared nevirapine once or twice daily with boosted atazanavir, each in combination with tenofovir/ emtricitabine in treatment-naive patients. The mean baseline CD4 ${ }^{+}$ count was 184 cells/ $\mu \mathrm{L}$, and the mean baseline viral load was $5.1 \log _{10}$ copies/mL. In this study, nevirapine was noninferior to boosted atazanavir in terms of the proportion of patients with a viral load of less than 50 copies/mL at week 48. Although nevirapine and boosted atazanavir appeared equally well tolerated, more patients discontinued nevirapine treatment due to adverse events.

Alternative Antiretroviral Strategies: A Comparison of Three Initial Regimens (ALTAIR) (54) was a three-arm, open-label study that compared a PI-based regimen (boosted atazanavir/tenofovir/ 
emtricitabine) with an NNRTI-based regimen (efavirenz/tenofovir/emtricitabine) and a quadruple NRTI regimen (zidovudine/ abacavir/tenofovir/emtricitabine) in treatment-naive patients. The mean baseline $\mathrm{CD}^{+}$count was 229 cells/ $\mathrm{LL}$ and baseline viral load was approximately $4.69 \log _{10}$ copies $/ \mathrm{mL}$. The boosted atazanavir and the quadruple NRTI arms were noninferior to efavirenz with respect to baseline changes in viral load, but most secondary endpoints showed that the quadruple NRTI regimen was significantly inferior to efavirenz. There were no substantive differences between the efavirenz and boosted atazanavir arms.

ACTG 5202 (55) compared atazanavir/r with efavirenz, either in combination with either tenofovir/emtricitabine or abacavir/ lamivudine. The median baseline viral load was $4.7 \log _{10}$ copies $/ \mathrm{mL}$, while the median baseline $\mathrm{CD}^{+}$count was 230 cells/ $\mu \mathrm{L}$. Efficacy, as measured by time to viral failure, was similar for both efavirenz and atazanavir/r combined with either NRTI combination. However, tolerability (time to change of regimen) and safety (time to grade $3 / 4$ sign/symptom or laboratory toxicity) were significantly better for atazanavir/r than for efavirenz when combined with abacavir/lamivudine; however, tolerability and safety was similar for the these agents when combined with tenofovir/ emtricitabine.

\section{Integrase strand transfer inhibitors}

Raltegravir is the first approved member in the class of integrase strand transfer inhibitors and now forms the basis for a DHHS-preferred regimen. STARTMRK was a randomized, double-blind trial comparing raltegravir with efavirenz, both in addition to tenofovir/emtricitabine. The mean baseline viral load was $5.0 \log _{10}$ copies $/ \mathrm{mL}$, and the mean baseline $\mathrm{CD}^{+}$count was 218 cells/ $\mu \mathrm{L}$. At 48 weeks, raltegravir was noninferior to efavirenz in the percentage of patients achieving a viral load of less than 50 copies $/ \mathrm{mL}$. Interestingly, the time for patients to reach this level of viral load was significantly shorter for raltegravir than for efavirenz, possibly because raltegravir acts at a later stage in the HIV life cycle than efavirenz. In addition, raltegravir showed a significantly greater change in $\mathrm{CD}^{+}$count than efavirenz. Significantly more efavirenz patients than raltegravir patients reported adverse effects, including central nervous system adverse events, although the incidence of severe adverse events was low in each group (56). An analysis of subgroups showed that both agents demonstrated consistent activity regardless of the subgroup analyzed, such as high versus low baseline viral load and various demographic parameters (57).

Study 004 was a randomized, double-blind, dose-ranging study that had a similar design to STARTMRK, except that raltegravir was tested at four doses for 48 weeks after which all continuing raltegravir patients were placed on a single-dose regimen for another 48 weeks. By the end of week 48, the four raltegravir arms showed similar reductions in viral load. At 96 weeks, both regimens showed similar results for the proportion of patients with a viral load of less than 400 copies/mL and less than 50 copies $/ \mathrm{mL}$, and for $\mathrm{CD}^{+}$count increases. As in STARTMRK, adverse drug reactions appeared less frequently with raltegravir than with efavirenz. Neuropsychiatric adverse events (abnormal dreams, depression, nightmares, suicidal ideation, suicide attempt, dizziness, somnolence, adjustment disorder with depressed mood, depressed mood and insomnia) were more frequent in the efavirenz group, primarily due to differences in incidence of dizziness and abnormal dreams (58).

\section{NRTI}

Issues such as lipodystrophy, mitochondrial toxicity and twice-daily dosing (for zidovudine and stavudine) have limited the use of the older first-line agents. Study ACTG 5202, discussed previously, also compared abacavir/lamivudine with tenofovir/emtricitabine, both in combination with efavirenz or atazanavir/r $(55,59)$. At 60 weeks, in patients with higher viral loads $(100,000$ copies/mL HIV RNA or greater), there was a shorter time to virological failure with abacavir/lamivudine versus tenofovir/emtricitabine, resulting in the unblinding of the higher viral load stratum. There was no difference in baseline changes of $\mathrm{CD}^{+}$counts at 48 weeks. The time to the first adverse event was also significantly shorter in the abacavir/lamivudine group (59). At the end of the study, in the lower viral load stratum, there was no difference between the two NRTI regimens in time to virological failure. There was no difference in safety events as previously defined between abacavir/ lamivudine and tenofovir/emtricitabine when they were combined with atazanavir/r, but there was a shorter time to a safety event with abacavir/lamivudine than tenofovir/emtricitabine when combined with efavirenz. The time to a tolerability event was shorter for abacavir/lamivudine than for tenofovir/emtricitabine when combined with either atazanavir/r or efavirenz (55).

The Kivexa versus Truvada Both Administered with Sustiva, in ART-naive subjects (ASSERT) trial (60) compared abacavir/ lamivudine with tenofovir/emtricitabine, both in combination with efavirenz. The primary end point was eGFR, which did not differ between groups. The median baseline viral load was approximately $5 \log _{10}$ copies $/ \mathrm{mL}$, and the median baseline $\mathrm{CD} 4^{+}$count was approximately 235 cells/ $\mu \mathrm{L}$. At 48 weeks, more tenofovir/emtricitabine than abacavir/lamivudine subjects achieved viral loads of less than 50 copies $/ \mathrm{mL}$, and patients in the latter group were more likely to report serious adverse events. Abacavir/lamivudine patients had smaller decreases in hip and lumbar spine bone mineral density than patients in the tenofovir/emtricitabine group.

The HIV study Head-to-head Epzicom and Truvada (HEAT), also compared abacavir/lamivudine with tenofovir/emtricitabine, each in combination with lopinavir/r $(61,62)$. The median baseline viral load was $4.9 \log _{10}$ copies $/ \mathrm{mL}$, and the baseline CD4 ${ }^{+}$count was 202 cells $/ \mu L$. At 48 weeks, abacavir/lamivudine was noninferior to tenofovir/emtricitabine for viral response to less than 50 copies $/ \mathrm{mL}$ and to less than 400 copies/mL. Abacavir/lamivudine appeared to cause a slight but nonsignificant increase in $\mathrm{CD}^{+}{ }^{+}$count. The virological response was similar in both groups when results were stratified into low (less than 100,000 copies/mL) and high (100,000 copies/mL or greater) groups. The latter results seem to contradict the results of ACTG 5202, which showed a shorter time to virological failure with abacavir/lamivudine. The regimens displayed similar tolerability.

\section{Guidelines}

With the exception of the DHHS, the guidelines previously mentioned recommend individual members of each drug class that can belong a regimen; the DHHS now specifies recommended regimens because not every possible combination is supported by clinical trial data. All of the guidelines recommend efavirenz or an r-boosted PI as the mainstay of treatment, in combination with two NRTIs (1-5).

The choice of NNRTI is one instance of complete uniformity of recommendation among the guidelines previously mentioned, more so than for the other categories of treatment. Efavirenz is the standard of care for patients receiving NNRTI-based ART, with no approved drugs to supplant this role at the current time. Only the EACS still recommends a role for nevirapine (limited as it may be) in the treatment of NNRTI-naive patients (1-5).

The choice of PI is more complicated than that of NNRTIs because many more PIs have been shown to be highly effective in combination with NRTIs. Boosted PIs that are part of DHHS-preferred regimens 
are atazanavir/r and darunavir/r, while British Columbia recommends lopinavir/ $\mathrm{r}$ and atazanavir/r, although the British Columbia recommendation was made before the Canadian approval of darunavir for initial treatment. The remainder of the guidelines recommend all of these boosted PIs along with saquinavir $/ \mathrm{r}$ because there are no randomized trials at approved doses comparing these regimens with one another, with the exception of studies comparing boosted PIs with lopinavir/r. None of the guidelines prioritizes NNRTI- or PI-based regimens over the other; however, the Quebec guidelines give a greater strength of recommendation to efavirenz than to boosted PIs (1-5). As a late addition to the armamentarium, only the DHHS and Quebec guidelines suggest a role for raltegravir in the treatment-naive patient, in combination with two NRTIs $(4,5)$.

Tenofovir/emtricitabine is now the only DHHS-preferred NRTI component and is recommended by the other guidelines (1-5). Zidovudine, didanosine and stavudine are no longer recommended for use in treatment-naive patients, although zidovudine is still recommended in pregnancy. Quebec (5) also recommends tenofovir/lamivudine and abacavir/lamivudine as NRTI duos; the latter combination listed equally in the EACS and International AIDS Society USA guidelines (1-5).

\section{Capsule (1-5)}

- The mainstay of treatment is either an NNRTI or a boosted PI along with two NRTIs.

- Efavirenz is the NNRTI of choice.

- Boosted atazanavir or boosted darunavir are the standard of care among the PIs, but some guidelines also recommend boosted lopinavir and boosted saquinavir.

- The choice between NNRTI- and PI-based therapy is specific to the individual patient.

- Raltegravir, an integrase strand transfer inhibitor, can also be used for the treatment of naive patients.

- Tenofovir/emtricitabine is frequently the standard of care for NRTIs; some guidelines also recommend abacavir/lamivudine.

\section{LIFELONG TREATMENT CONSIDERATIONS}

Now that HIV infection is regarded as a chronic disease, issues such as lifetime treatment must be taken into account. As HIVinfected patients age, they will encounter the usual vicissitudes of aging: hypertension, diabetes, osteoporosis, malignancies, etc. When selecting ART, these future considerations must be taken into account.

\section{Alteration of lipid parameters}

The components of ART have varying effects on lipid parameters such as high-density lipoprotein cholesterol (HDL-C), low-density lipoprotein cholesterol (LDL-C) and triglycerides. Study ACTG A5142 examined the effect of stavudine, zidovudine and tenofovir on lipid parameters. This study found that the three NRTIs increased total cholesterol, with stavudine producing significantly increased total cholesterol versus tenofovir. Other comparisons between the NRTIs yielded nonsignificant differences. Similar results were found for increases in non-HDL-C, while smaller differences were found for increases in HDL-C and triglycerides (63).

The HEAT study showed that both abacavir/lamivudine and tenofovir/emtricitabine increased lipid values; however, the changes were somewhat larger in the former group (62).

Within the PI class, the CASTLE study (43) showed that lopinavir/r had a more deleterious effect on total cholesterol, nonHDL-C and triglycerides than atazanavir/r, and that more patients in the former group than in the latter required lipid-lowering therapy. The ARTEMIS study (45) also showed that darunavir/r produced smaller increases in total cholesterol than lopinavir/r. The Gemini study showed that saquinavir/r produced lipid increases similar to lopinavir/ $\mathrm{r}$ with the exception of triglycerides, which were higher in the latter group (49). The KLEAN trial showed that fosamprenavir $/ \mathrm{r}$ and lopinavir/ $\mathrm{r}$ produced similar increases in total cholesterol, LDL-C, HDL-C and triglycerides (47). Both saquinavir and fosamprenavir were administered with $\mathrm{r}$ at $200 \mathrm{mg}$ daily. This may explain the divergent lipid results for these two drugs versus atazanavir and darunavir with which $\mathrm{r}$ is administered at $100 \mathrm{mg}$ daily $(43,45,47,49)$. This is supported by the results of the ALERT trial, which showed that investigational fosamprenavir/r $100 \mathrm{mg}$ and atazanavir/r produced similar changes in HDL-C, LDL-C and total cholesterol, but triglyceride levels were higher with boosted fosamprenavir (50). Thus, it appears that $\mathrm{r}$ is the main culprit in altering lipid values in boosted PI regimens.

\section{Treatment with statins}

Statins are highly effective lipid-lowering agents, but their use in patients receiving ART can be complicated by various drug interactions (64). As a class, NRTIs are not metabolized by the cytochrome P450 system and, thus, tend not to have drug-drug interactions with lipid-lowering agents. However, PIs tend to interact with statins, but not all equally. Simvastatin and lovastatin should not be used with PIs. Fluvastatin and pravastatin have a lower potential for drug interactions, except for possible interactions between the latter and darunavir/r. However, pravastatin is less potent than either atorvastatin or rosuvastatin and was inferior to atorvastatin in preventing CV events in the Pravastatin or Atorvastatin Evaluation and Infection Therapy (PROVE-IT) study (65). Atorvastatin and rosuvastatin should be started at the lowest possible dose and titrated based on efficacy and tolerability (4).

Silverberg et al (66) conducted a retrospective cohort study in patients with elevated LDL-C or triglycerides to compare the response to lipid-lowering medication of patients with HIV infection versus those without HIV infection. HIV-infected patients had a significantly poorer response to statins than uninfected individuals, but there was no difference between patients taking different classes of antiretrovirals. Similarly HIV-positive patients with elevated triglyceride levels did not respond as well as the non-HIV-infected comparators to treatment with gemfibrozil. However, the response to gemfibrozil varied by class, with patients receiving NNRTIs responding better than patients receiving PIs. Interestingly, while adherence to statins or gemfibrozil was similar between HIV-positive and -negative patients, more HIV-positive patients were more than $96 \%$ adherent to their lipid-lowering medication than their HIV-negative counterparts.

\section{CV risk}

Patients with pre-existing CV risk factors may be concerned that ART will add to their already higher than average CV risk. However, a large Veteran's Affairs retrospective cohort study (67) showed that while exposure to ART increased from 1993 to 2003, all-cause mortality fell dramatically, as did inpatient stays for MI, stroke or death from any cause. In the same time frame, inpatient stays for MI or their equivalent remained relatively constant. Thus, exposure to ART did not increase the risk of inpatient stays for serious CV events up to eight years after its introduction and after up to six years of individual use (Figure 3).

According to the D:A:D study, the CV risk factor profiles of HIV-positive patients has been worsening over time, from 1999 to 2000, and from 2005 to 2006. This has been attributed to an 


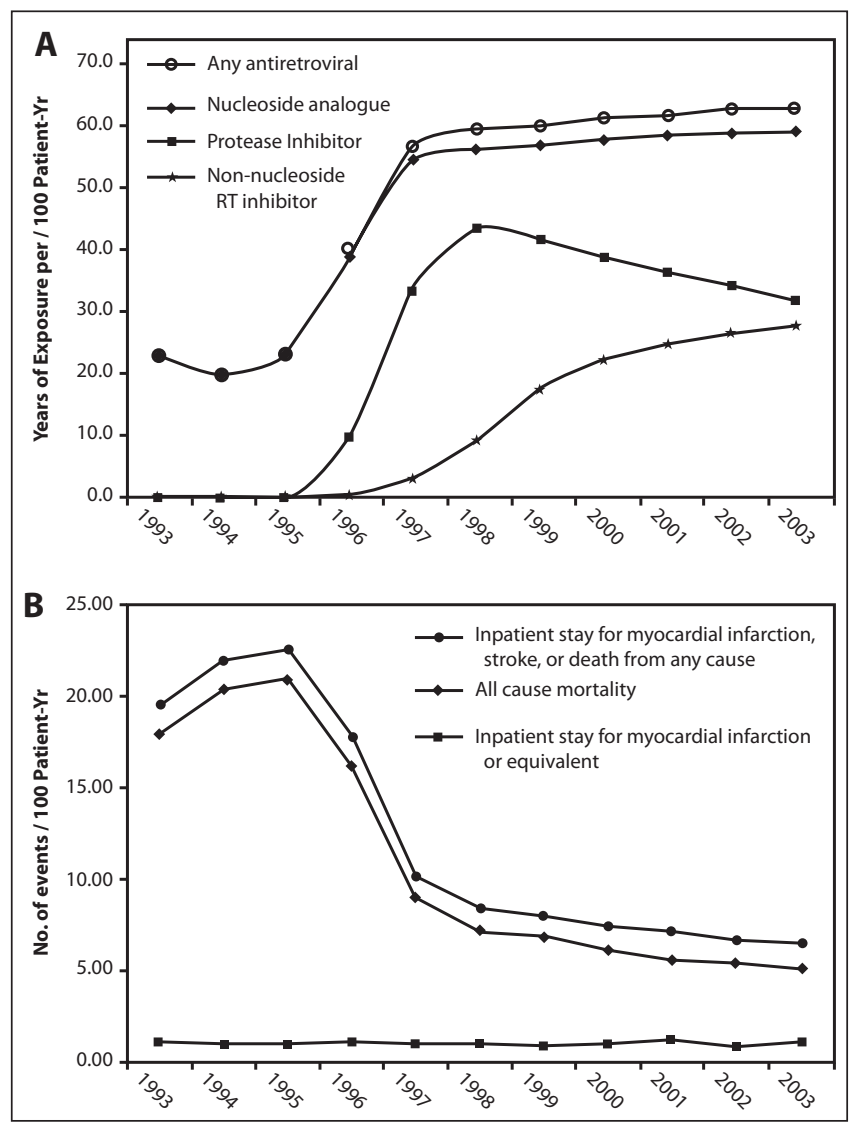

Figure 3) A Exposure rates to antiretrovirals in the 1993 to 2003 cohort. B Event rates in the 1993 to 2003 cohort. RT Reverse transcriptase. No Number; Yr Years. Adapted from reference 67

increase in the proportion of patients who, among other factors, are older, have a history of CV disease, diabetes mellitus and hypertension. With time, more patients received lipid-lowering therapy or invasive $\mathrm{CV}$ procedures. The prevalence of smoking decreased over that time period, but was still the most frequently occurring risk factor $(38 \%)$ in the latest time period (19).

Due to frequent pre-existing CV risk factors and the adverse effects that ART can have, aggressively lowering all reversible cardiac risk factors is in the patients' best interest.

\section{NNRTIs}

The D:A:D study revealed a significant relationship between the length of exposure to NNRTIs and the risk of an MI. When the data were adjusted - first for exposure to other antiretroviral drug classes and established CV risk factors (not including lipids), and then for lipid levels - this relationship lost significance (68). A newer analysis of the D:A:D data (42) showed that neither efavirenz nor nevirapine was associated with an increased risk of MI.

\section{PIs}

The D:A:D study also revealed a significant relationship between the length of exposure to PIs and the risk of an MI. When the data were adjusted as above, this relationship remained significant (68). There have not been sufficient patient-months of exposure to atazanavir or darunavir in the D:A:D study for MI risk to be calculated. Agence Nationale de Recherche sur le Sida (ANRS) CO-4, a nested case-controlled study (69), showed the occurrence of increasing risk of MI with cumulative exposure to lopinavir, amprenavir and fosamprenavir.
The newer D:A:D analysis (42) also examined PIs and showed that in this class, indinavir and lopinavir/ $\mathrm{r}$ were associated with a significantly increased risk of MI, while nelfinavir and saquinavir were not. In a nested, case-controlled study investigating the incidence of acute $\mathrm{MI}$ in patients receiving PIs, Durand et al (70) found an increased risk of MI with exposure to lopinavir and $r$ but not with atazanavir, fosamprenavir, indinavir, nelfinavir and saquinavir.

\section{NRTIs}

Investigating the incidence of acute MI in patients receiving NRTIs, Durand et al (70) found an increased risk of MI with exposure to abacavir, didanosine and stavudine. No such relationship was found for emtricitabine, lamivudine, tenofovir, zalcitabine and zidovudine. These results were supported by ANRS CO-4, which found that initiating treatment with abacavir increased the risk of $\mathrm{MI}$ in patients during the first year of exposure and with recent use (69).

Another analysis of the D:A:D data (71) showed that recent exposure to abacavir and didanosine was associated with an increased risk of MI, but exposure to zidovudine, stavudine or lamivudine were not. An extension of this analysis (42) showed that neither zalcitabine nor tenofovir was associated with an increased risk of MI.

The SMART study (72) investigated CV events in patients from the continuous ART arm of the study. The current use of abacavir was associated with an increased risk of CV events, including MI, major CV events (composite of MI, stroke, surgery for coronary artery disease, and CV disease death), and expanded $\mathrm{CV}$ events (major CV events and congestive heart failure, peripheral vascular disease, coronary artery disease requiring drug treatment and unwitnessed deaths) versus other NRTIs excluding didanosine, which was not associated with increased CV risk.

Contrary to the studies above, a Veteran's Affairs study showed no significant association between acute MIs or cerebrovascular accidents and abacavir use (73). These results are supported by a meta-analysis by Brothers et al (74) of 52 GlaxoSmithKline-sponsored adult clinical trials in treatment-naive and treatment-experienced patients. MI rates were comparable regardless of whether patients were exposed to abacavir. An analysis of treatment-naive patients randomly assigned to abacavir as part of their initial treatment in five ACTG studies (AIDS Clinical Trials Group Longitudinal Linked Randomized Trials [ALLRT] cohort) also found no association between abacavir use and MI or severe CV risk (75).

\section{Capsule}

- HIV is a chronic disease and lifelong treatment is expected.

- Treatment regimens can vary with respect to atherogenicity.

- In boosted-PI regimens, $r$ seems to be largely responsible for dyslipidemia.

- There are studies that link exposure to specific antiretroviral drugs to a higher risk of CV disease.

- Statins may not be as effective in HIV-positive patients as they are in HIV-negative patients.

- Atorvastatin and rosuvastatin are the most potent statins; they should be started at the lowest possible dose and be titrated based on efficacy and tolerability.

- Certain antiretroviral drugs expose patients to increased CV risk.

\section{ADHERENCE, FORGIVENESS AND RESISTANCE}

The parameters of adherence, forgiveness and resistance are intimately tied together. If the patient is not optimally adherent to ART, resistance can develop, although this can be mitigated by several drug characteristics including potency, genetic barrier to resistance and half-life. This establishes the notion of 'forgiveness'. Although not a formally defined term, it has come to mean the measure of how 
much adherence to treatment could decline, yet still result in the achievement and maintenance of viral suppression (76). PIs generally have a high genetic barrier to resistance (multiple mutations in the protease gene are generally necessary for clinical resistance), while NNRTIs have a lower barrier (a single mutation at critical positions in the reverse transcriptase gene is sufficient for clinical resistance) (4). However, drug potency (77), and a longer half-life permit greater forgiveness (76) - NNRTIs are certainly forgiving in patients who are sporadically suboptimally adherent. However, if a patient misses several consecutive doses, then an extremely long half-life of one drug of a multidrug regimen could conceivably promote resistance because it may result in the equivalence of monotherapy or dual therapy as the effect of the shorter half-life drugs in the treatment regimen wear off (76). The estimate of how much adherence is required for viral suppression is changing.

It was previously reported (78) that $95 \%$ adherence with ART was required to maintain viral suppression, but this is not the case with most current regimens because these data were from the unboosted PI regimen era, when many patients also had nucleoside resistance mutations from previous nucleoside monotherapy. Two recent studies $(77,79)$ showed that high rates of viral suppression could be attained with adherence rates of as little as 54\% and 75\%. Two critical factors in forgiveness are the potency and half-life of the drug treatment (76).

Previous studies have also shown that patients most at risk of treatment failure were those who were $80 \%$ to $90 \%$ adherent. Tam et al (80) went further and investigated adherence rates (as measured by prescription refills or plasma drug concentrations) and their effect on the development of resistance in PIs, NNRTIs and NRTIs. NNRTI and lamivudine mutations were significantly more frequent in patients who were $80 \%$ to $90 \%$ adherent, as measured by prescription refills, than in patients who were at least $95 \%$ adherent. For the remainder of the NRTIs and PIs, the relationship between adherence level and development of resistance was weaker (Figure 4). When adherence was measured by prescription refills and plasma drug concentrations, peak development of resistance to NNRTIs and lamivudine occurred in the lowest strata of adherence. There was effectively no relationship between adherence and resistance for the remainder of the NRTIs or the PIs. However, patients who were highly adherent - measured by prescription refills but with inconsistent drug levels - were more prone to develop resistance mutations for all drug classes. It is important to note that the PIs the patients received in this cohort were unboosted.

Rosenblum et al (81) investigated the probability of treatment failure just after viral suppression was achieved versus the probability of treatment failure after 12 months of viral suppression, in relation to the level of adherence. They found that as long as adherence was greater than $50 \%$, the risk of virological failure diminished with time. They also concluded that the longer that HIV was suppressed, the more leeway there was in how adherent to treatment the patient was required to be - meaning that forgiveness increased with the length of time that the virus was suppressed.

While the concept of forgiveness allows for a certain margin of flexibility in terms of adherence to drug therapy, it is still highly desirable to maximize adherence to drug treatment. In a European study, Protopopescu et al (82) investigated the factors affecting adherence over a 10-year period. Nonadherence was correlated with several factors, including drug adverse events, more frequent daily dosing regimens and symptomatic disease. Patients found to be less adherent were those: with symptoms of depression; who consumed alcohol daily; who felt a lack of support from their principal partner; were born outside the European Union; who were younger; and those who had children.

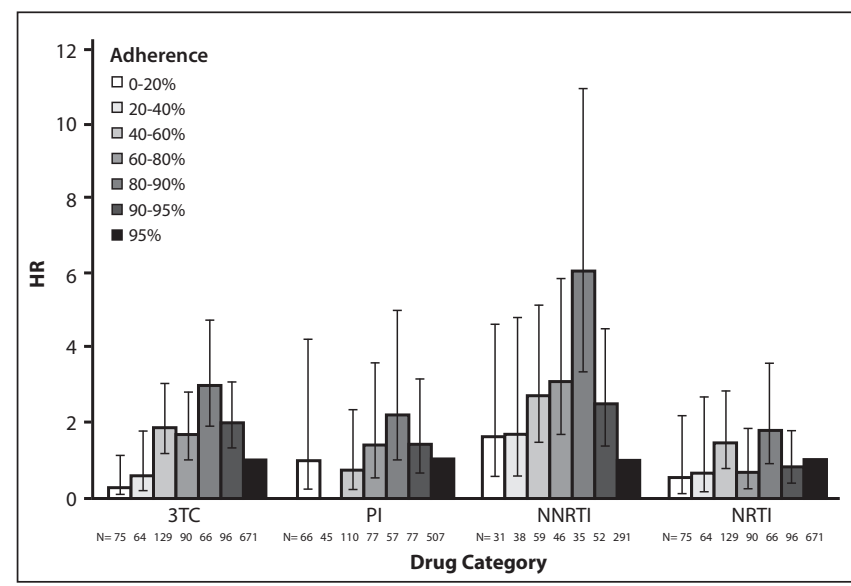

Figure 4) Hazard ratios (HR) for the risk of detection of laminudine (3TC), protease inhibitor (PI), non-nucleoside reverse transcriptase inhibitor (NNRTI), and nucleoside reverse transcriptase inhibitor (NRTI) resistance mutations in multivariable models adjusted for baseline demographics, plasma viral load and CD4-positive T cell count. Antiretroviral exposure was adjusted as a time-dependent variable. Stratified adherence levels of (1) $0 \%$ to $20 \%$; (2) 20\% to $40 \%$; (3) $40 \%$ to $60 \%$; (4) $60 \%$ to $80 \%$; (5) $80 \%$ to $90 \%$; and (6) $90 \%$ to $95 \%$ were compared with the (7) 95\% refill level (ie, HR=1.0). Results are reported as HRs with $95 \%$ CIs. Adapted from reference 80

Another prospective cohort study (83) showed that $80 \%$ adherence to boosted PI or NNRTI regimens resulted in a failure rate of less than $10 \%$ (more than 200 copies/mL of HIV RNA). The predictors for adherence were the drug regimen, the total number of pills per day and the number of doses per day. Adherence was significantly greater in patients on NNRTI-based regimens than in patients on boosted PI-based regimens; however, there was no significant difference between the two regimens in terms of treatment failure rate. There was a significant but small inverse relationship between the number of pills per day and adherence, but no difference in adherence between once- or twice-daily regimens, although both of these showed greater adherence than three- or four-times-daily regimens.

The single-arm Five Days On, Two Days Off (FOTO) study (84) investigated the effect of changing from a daily regimen to a five days on, two days off regimen (FOTO regimen) on viral load in patients who were virally suppressed for at least three months at study enrollment. At enrollment, approximately equal numbers of patients were receiving an efavirenz-based regimen, a nevirapinebased regimen or a PI-based regimen. Viral suppression (less than 50 copies HIV-RNA/mL) was sustained over 48 weeks in $90 \%$ of patients and in all efavirenz-treated patients. To expand on the results above, patients who were virally suppressed (less than 50 copies HIV-RNA/mL) while on efavirenz, tenofovir and emtricitabine were randomly assigned to daily treatment or to a FOTO regimen with the same drugs. The FOTO regimen maintained viral suppression for the 48-week duration of the study (ie, noninferior to daily therapy) with no significant differences in $\mathrm{CD} 4^{+}$counts. The FOTO regimen was strongly preferred by patients (85). The FOTO study indicated that patients receiving a fixed-dose combination of efavirenz/tenofovir/emtricitabine can have excellent virological results with $71 \%$ adherence (five doses of seven in a week).

Earlier in the present document, the timing of treatment initiation and its effect on outcomes was discussed, with the data generally supporting the notion of 'earlier is better'. However, in an 


\section{TABLE 3}

\section{Fixed-dose antiretroviral agents}

Dual nucleoside reverse transcriptase inhibitor

Tenofovir/emtricitabine

Zidovudine/lamivudine

Abacavir/lamivudine

Boosted protease inhibitor

Lopinavir/ritonavir

Dual class antiretroviral therapy

Efavirenz/tenofovir/emtricitabine

observational study, Wood et al (86) compared adherence (as measured by prescription refills) and survival in patients with

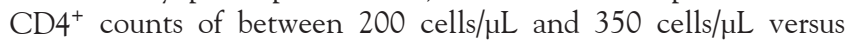
patients with $\mathrm{CD}^{+}$counts of at least 350 cells/ $\mu \mathrm{L}$, and discovered that there was no survival advantage in starting ART at the higher $\mathrm{CD}^{+}$stratum in adherent patients. However, adherent patients in the higher $\mathrm{CD}^{+}$stratum had greater survival than nonadherent patients in the lower $\mathrm{CD}^{+}{ }^{+}$stratum. The authors concluded that adherence was the key factor to treatment success in patients with a CD4 ${ }^{+}$count of greater than 200 cells $/ \mu \mathrm{L}$.

Pill burden and frequency of administration can affect adherence. Attempts to reduce the pill burden as much as possible have resulted in fixed-dose combinations of several antiretroviral regimens (Table 3). For an NNRTI-based regimen, there is the option of efavirenz/tenofovir/emtricitabine as a one-tablet, once-daily fixed-dose regimen, provided that all three drugs are appropriate for a given patient. NRTI combinations have also been simplified with the advent of one-tablet, once-daily, fixed-dose combinations of abacavir with lamivudine, and of tenofovir with emtricitabine, and the twice-daily fixed dose combination of zidovudine with lamivudine. The development of PIs, however, has not kept pace. Although lopinavir/ $\mathrm{r}$ is available as a fixed-dose tablet, four tablets per day are required. Boosted atazanavir has the smallest pill burden and lowest required $\mathrm{r}$ dose, with one $\mathrm{r} 100 \mathrm{mg}$ capsule plus one atazanavir $300 \mathrm{mg}$ capsule each once daily (Table 4).

\section{Capsule}

- Lack of optimal adherence can result in the development of resistance.

- Potency, high genetic barrier to resistance and long half-life can, to a certain degree, mitigate the effects of lack of adherence.

- Previously, 95\% adherence was required for ongoing viral suppression, but this is lower with the current therapeutic armamentarium.

- For NNRTIs, the FOTO trial using a five days on, two days off dosing of a fixed-dose combination of efavirenz/tenofovir/ emtricitabine showed that viral suppression could be maintained with $71 \%$ adherence.

- For PIs, boosted atazanavir has the smallest pill burden and lowest required $\mathrm{r}$ dose, while lopinavir/ $\mathrm{r}$ is the only fixed-dose combination boosted PI.

- For NRTIs, fixed-dose combinations of tenofovir/ emtricitabine and abacavir/lamivudine are available.

\section{COMORBIDITIES AND OTHER FACTORS FURTHER COMPLICATING TREATMENT DECISIONS}

As previously mentioned, inflammation and immune activation may be responsible for some of the various comorbidities encountered in HIV-infected individuals. These include AIDS-defining and non-AIDS-defining cancer, and HIV-associated nephropathy.

\section{Malignancies}

In an analysis of two large prospective cohort studies, Patel et al (87) found that the incidence of several non-AIDS-defining cancers was significantly higher in HIV-positive individuals than in the general population. These included anal, colorectal, liver, lung, oropharyngeal, renal and vaginal cancers, Hodgkin's lymphoma, melanoma and leukemia. Anal, vaginal and oropharyngeal cancers may be explained by the increased incidence of human papillomavirus infection in HIV-infected persons; however, human papillomavirus infection does not explain the increased incidence of the other non-AIDS-defining cancers. Curiously, the incidence of prostate cancer was higher in the general population. A low nadir $\mathrm{CD}^{+}$count was associated with an increased risk of anal, colorectal and lung cancer.

Guiguet et al (88) reported an increased risk of AIDS-defining cancers (Kaposi's sarcoma and non-Hodgkin's lymphoma) and non-AIDS-defining cancers (Hodgkin's lymphoma, lung cancer and liver cancer) in patients with $\mathrm{CD}^{+}$counts of 350 cells $/ \mu \mathrm{L}$ to 499 cells $/ \mu \mathrm{L}$, or less than 50 cells $/ \mu \mathrm{L}$ versus more than 500 cells $/ \mu \mathrm{L}$. The increased risk was greater in the lower $\mathrm{CD} 4^{+}$cell stratum. This also supports initiating ART at higher $\mathrm{CD}^{+}$counts than previously believed.

\section{HIV-associated nephropathy}

HIV-associated nephropathy develops almost exclusively in patients of African descent and can occur at any $\mathrm{CD} 4^{+}$count. It is the most frequent cause of chronic kidney disease (CKD) leading to end-stage renal disease in the HIV-infected population (4), although it may only occur rarely in Canada. Kalayjian et al (89) showed that viral suppression was associated with GFR improve-

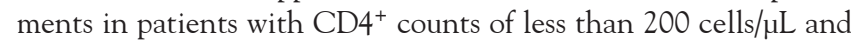
impaired baseline renal function. In addition, GFR improvements independent of viral suppression were seen in patients with $\mathrm{CD}^{+}$ counts of 200 cells $/ \mu \mathrm{L}$ or higher, supporting early treatment in these patients.

\section{Renal dysfunction}

As patients age, there is an increased likelihood of developing renal dysfunction and, as noted previously, renal dysfunction is a predictor of mortality (18). Patients with diabetes mellitus or hypertension are also at increased risk of renal dysfunction as well as other sequelae.

Choice of ART can also impact renal dysfunction. In a nonrandomized cohort study, Kirk et al (90) showed that 3.3\% of HIVpositive patients developed CKD. Increasing cumulative exposure of tenofovir, indinavir, atazanavir and lopinavir were associated with a significantly increased rate of CKD. Patients at greatest risk of CKD were those with a low eGFR, those with traditional CKD risk factors and those who started therapy with tenofovir.

\section{Antiretroviral agents requiring dose adjustment in renal dysfunction}

Of the NRTIs, lamivudine, tenofovir and emtricitabine require dose adjustment in patients with renal dysfunction; thus, the use of fixed-dose combinations including these agents is generally not recommended in patients with significant renal dysfunction. At a creatinine clearance of lower than $50 \mathrm{~mL} / \mathrm{min}$, tenofovir and emtricitabine dosages should be reduced to once every two days, although, conceivably, this could make adherence to treatment more difficult because whichever PI or NNRTI was being given concomitantly would still be once daily. If a patient with renal impairment were receiving tenofovir/emtricitabine, this NRTI combination could be replaced by abacavir/lamivudine, 
TABLE 4

Dosing of boosted protease inhibitors (PI)

\begin{tabular}{lll}
\hline Boosted PI regimen & Dose per day & Ritonavir dose \\
\hline Atazanavir & $1300 \mathrm{mg}$ tablet once daily & $1100 \mathrm{mg}$ capsule once daily \\
Darunavir & $2400 \mathrm{mg}$ tablets once daily & $1100 \mathrm{mg}$ capsule once daily \\
Fosamprenavir & $2700 \mathrm{mg}$ tablets once daily & $2100 \mathrm{mg}$ capsules once daily \\
Lopinavir & $4200 / 50 \mathrm{mg}$ tablets once daily & $200 \mathrm{mg}$ (coformulated with lopinavir) \\
Saquinavir & $2500 \mathrm{mg}$ tablets twice daily & $1100 \mathrm{mg}$ capsule twice daily \\
\hline
\end{tabular}

bearing in mind that while the abacavir dose does not require modification, the dose of lamivudine does need adjustment. At a creatinine clearance of $50 \mathrm{~mL} / \mathrm{min}$ or lower, the lamivudine dose could be halved, but remain once daily, which would preclude the use of the fixed-dose combination of abacavir/lamivudine (4).

\section{Antiretroviral agents not requiring dose adjustment in renal dysfunction}

PIs do not require dosage adjustment in patients with renal impairment, but atazanavir/ $\mathrm{r}$ requires adjustment for patients requiring hemodialysis. Neither efavirenz nor, as stated previously, abacavir require dose adjustment (4).

\section{Women of child-bearing potential}

Women of child-bearing potential pose two treatment challenges. Some antiretroviral drugs can interact with oral contraceptives and lower ethinyl estradiol concentrations as stated above; therefore, women taking antiretroviral drugs should use alternative or additional contraception. The second major issue is that efavirenz has been shown to be teratogenic in nonhuman primates. In addition, neural tube defects have been reported in the newborns of a few mothers who were exposed to efavirenz in their first trimester of pregnancy. Thus, the use of efavirenz should be avoided in women with high pregnancy potential (women trying to conceive or who are sexually active with men and are not using effective and consistent contraception) (4). However, it should be noted that as of July 2009, efavirenz has not been associated with an increased incidence of birth defects in the Antiretroviral Pregnancy Registry (41), based on a sufficient number of first trimester exposures adequately powered to detect at least a two-fold increase in the risk of overall birth defects.

\section{Methadone use \\ NRTIs do not appear to interact pharmacokinetically with meth- adone in any clinically significant way; however, the same cannot be said about NNRTIs. Pharmacokinetic interactions between meth- adone and NNRTIs have been well characterized and can be clinic- ally significant. Efavirenz and nevirapine are potent inducers of the cytochrome P450 system, which results in decreased methadone levels that can cause opiate withdrawal symptoms. PIs can also interact with methadone. Lopinavir, but not $r$, reduces methadone concentrations, whereas atazanavir has no effect and saquinavir does not affect free unbound methadone (4). The usual daily dis- pensing of methadone provides an opportunity for monitoring adherence to ART, especially with once-daily ART regimens.}

\section{HBV coinfection}

ART using drugs active against both HIV and HBV may be able to slow liver disease progression by preserving or restoring immune function, reducing HIV-related immune activation and inflammation, and by directly suppressing HBV replication (4). The key consideration in treating the HBV-HIV-coinfected patient is to not use only one nucleoside drug that is active against HBV (even though it may be sufficient for the HBV infection) because this can generate drug-resistant mutants of HIV. Therefore, whether the goal is to treat both infections or only HIV, the NRTI combination used to treat HIV should consist of two NRTIs that are active against HBV (eg, tenofovir with either lamivudine or emtricitabine) (4), together with a third agent to fully suppress HIV. Consideration should be given to treating HBV-coinfected patients at any $\mathrm{CD}^{+}$count.

\section{HCV coinfection}

HIV coinfection can accelerate HCV liver disease, particularly at low $\mathrm{CD}^{+}$counts. However, several cohort studies have shown that ART is associated with a decrease in the progression of $\mathrm{HCV}$ liver disease; four studies demonstrated a reduction in liver-related mortality. Although not substantiated in randomized trials, this indicates that initiation of ART at higher $\mathrm{CD}^{+}{ }^{+}$counts is beneficial for HIV-HCV coinfected patients (91).

d'Arminio Monforte et al (92) reported that HIV patients coinfected with HCV were at an increased risk of developing an AIDS-defining illness (including bacterial and mycotic diseases) compared with noncoinfected patients, and that cirrhotic coinfected patients were at higher risk than noncirrhotic coinfected patients and noncoinfected patients for mycotic and bacterial infections, toxoplasmosis and AIDS-defining illnesses. Furthermore, the risk of HCV-induced cirrhosis is three-times higher in HIV-positive individuals than in those who are HIV negative. A common strategy is to defer treating $\mathrm{HCV}$ in patients with $\mathrm{CD}^{+}{ }^{+}$counts of less than 200 cells $/ \mu \mathrm{L}$ until their $\mathrm{CD}^{+}$counts have recovered as a result of ART. Conversely, consideration can be given to treating at any $\mathrm{CD}^{+}$level to delay scarring of the liver.

If $\mathrm{HCV}$ is to be treated with pegylated interferon (peginterferon) plus ribavirin, neither zidovudine $(93,94)$ nor didanosine (94-96) should be used concomitantly. Several studies have reported that concomitant abacavir therapy is associated with a reduced response to peginterferon plus ribavirin (97-99), whereas other studies have not found such an association $(100,101)$. In a multicentre Spanish study of 256 subjects (99), concomitant tenofovir therapy was an independent predictor of a sustained virological response to peginterferon plus ribavirin.

\section{Polypharmacy and drug interactions}

Due to the number of drugs that HIV-infected patients take and the number of interactions between these drugs, a discussion of drug interactions is beyond the scope of the present paper. However, readers are referred to the numerous online drug interaction tools.

\section{Capsule}

- Many non-AIDS-related cancers are more frequent in HIV-infected individuals than in noninfected individuals.

- Canadians of African descent are at risk of HIV-associated nephropathy.

- Renal dysfunction can affect the disposition of some NRTIs; this may preclude the use of fixed-dose combinations. 
- Older patients do not respond as well to ART as younger patients.

- Efavirenz can increase ethinyl estradiol concentration, while PIs can decrease them; thus, complicating oral contraception and HRT.

- Women of child-bearing potential should not receive efavirenz unless they are using effective and consistent contraception.

- Various antiretroviral drugs can interact with methadone to reduce methadone concentrations; daily dispensing of methadone provides an opportunity to monitor adherence with ART.

- The HBV-coinfected patient should receive two NRTIs effective against HBV along with a third antiretroviral to fully suppress HIV.

- HIV coinfection can worsen HCV liver disease; drug interactions between certain NRTIs and peginterferon/ ribavirin can occur.

\section{PATIENT VIGNETTES}

Case 1: Young man who has sex with men

Age: 32 years

CD4+ count: 340 cells/ $/ \mathrm{L}$

Viral load: 10,000 copies/mL

Comorbidities: none

Resistance testing: no resistance detected

HLA-B*5701 status: negative

High-risk behaviours: unprotected sex with many partners raising concerns about virus transmission

Treatment selection process: discuss side effects and pill burden, selection is adjusted to preferences of treater and patient; balance toxicity of older regimens versus limited knowledge of durability of response to newer agents

Treatment options:

- Regimens:

- Efavirenz/tenofovir/emtricitabine; or

- Atazanavir/ $\mathrm{r}+$ tenofovir/emtricitabine or darunavir/ $\mathrm{r}$ (once daily) + tenofovir/emtricitabine; or

- Raltegravir + tenofovir/emtricitabine

- Other possible individual components:

- lopinavir/r or saquinavir/r or fosamprenavir/r

- abacavir/lamivudine

Case 2: Older man who has sex with men

Age: 50 years

CD4+ count: 410 cells $/ \mu \mathrm{L}$

Viral load: 400,000 copies $/ \mathrm{mL}$

Resistance testing: no resistance detected

HLA-B*5701 status: negative

CV risk factors: smoker; body mass index $=28 \mathrm{~kg} / \mathrm{m}^{2}$; blood pressure $120 / 80 \mathrm{mmHg}$ under treatment with a thiazide diuretic; LDL-C level of $2.5 \mathrm{mmol} / \mathrm{L}$ under treatment with atorvastatin (pretreatment LDL-C level of $3.9 \mathrm{mmol} / \mathrm{L}$ )

Serum creatinine: $82 \mu \mathrm{mol} / \mathrm{L}$ (normal)

Encourage lifestyle modification: smoking cessation, increase exercise, diet and weight loss

Maintain: blood pressure control, atorvastatin

Treatment options:

- Due to CV risk, avoid abacavir and lopinavir/r

- Due to viral load, avoid abacavir

- Use tenofovir/emtricitabine (tenofovir/lamivudine could also be used; this however, adds one pill)

- Consider efavirenz or saquinavir/r due to their CV safety profiles or raltegravir, atazanavir/ $\mathrm{r}$, or darunavir/ $\mathrm{r}$ for their lower impact on lipids

- No hard end point data (CV events) are available for atazanavir $/ \mathrm{r}$ and darunavir $/ \mathrm{r}$, and are not yet included in D:A:D analyses

- Due to the recent introduction of raltegravir into practice, there are no CV risk data yet

- Avoid nevirapine due to high baseline $\mathrm{CD}^{+}{ }^{+}$count

Case 3: Male IDU

Age: 32 years

CD4+ count: 320 cells $/ \mu \mathrm{L}$

Viral load: 80,000 copies/mL

Resistance testing: no resistance detected

HLA-B*5701 status: negative

History:

- Became an IDU at 16 years of age

- Psychiatric issues: bipolar, previous suicide attempts, major depression and treatment with quetiapine

- Previously incarcerated for theft and assault

Coinfection: HCV, genotype 1a

Laboratory values:

- Normal platelet count, prothrombin, albumin, creatinine and total bilirubin

- Alanine aminotransferase $90 \mathrm{U} / \mathrm{L}$

- Aspartate aminotransferase $60 \mathrm{U} / \mathrm{L}$

Abdominal examination: increased echogenicity on ultrasound; no liver biopsy, slightly enlarged spleen $(14 \mathrm{~cm})$

Treatment options:

- Fixed-dose combination efavirenz/tenofovir/emtricitabine

- Other options: atazanavir/r (potential hyperbilirubinemia); lopinavir/ $r$

Case 4: Married woman with heterosexual transmission

Race: Black

Age: 35 years

CD4+ count: 520 cells $/ \mu \mathrm{L}$

Viral load: 35,000 copies/mL

Previous treatment: nevirapine (single dose) in South Africa

Resistance testing: no resistance detected on a commercial Virco genotype test

HLA-B*5701 status: negative

Renal status: serum creatinine $220 \mu \mathrm{mol} / \mathrm{L}$; proteinuria 4g/24 h; consulting a nephrologist

Treatment options according to guidelines:

- Due to renal dysfunction, use abacavir and lamivudine; if a lamivudine dose reduction is required, then a fixed-dose combination is not advised

- Tenofovir is not recommended in patients with renal insufficiency if there are alternatives

- Efavirenz not recommended due to previous exposure to nevirapine resulting in a risk of treatment failure

- Efavirenz should only be recommended if there was proof that nevirapine was used in a fully suppressive regimen

- If nevirapine was used alone or with a brief course of zidovudine to prevent mother-to-child transmission, the risk of nevirapine resistance is too high, and efavirenz should be avoided

- Child-bearing potential

- If this patient mentions a desire for pregnancy, then efavirenz is not recommended due to the possible risk of fetal harm (DHHS) 
- The patient should be counselled on appropriate contraception; therapy should be modified if she decides to become pregnant

- Recommended treatment is abacavir/lamivudine plus a boosted PI such as atazanavir/r, lopinavir/r, saquinavir/r or fosamprenavir/ $\mathrm{r}$

- Raltegravir and darunavir/r are not as attractive options as the above recommendation due to lack of data of these agents in combination with abacavir/lamivudine

\section{CONCLUSION}

Studies have now shown that initiating ART at higher $\mathrm{CD}^{+}$counts improves survival. Early treatment can decrease the inflammation and immune activation that is responsible for end-organ damage in HIV-infected individuals. Early treatment may also help reduce virus transmission. It is generally accepted that ART should be started at a CD4 ${ }^{+}$count of no less than 350 cells $/ \mu \mathrm{L}$. The success of treatment can be maximized by assuring that the patient has been assessed for their willingness to start treatment.

There are many highly effective treatment options available that can be tailored to the needs of the individual patient based on

\section{REFERENCES}

1. British Columbia Centre for Excellence in HIV/AIDS. Therapeutic guidelines: Antiretroviral treatment of adult HIV infection. $<$ http://www.cfenet.ubc.ca/webuploads/files/Adult_therapeutic_ guidelines_2009.pdf> (Accessed on September 29, 2009).

2. European AIDS Clinical Society. Guidelines: Clinical management and treatment of HIV infected adults in Europe. <http://www. europeanaidsclinicalsociety.org/guidelinespdf/1_Treatment_of_HIV_ Infected_Adults.pdf> (Accessed on December 4, 2009).

3. Hammer SM, Eron JJ Jr, Reiss P, et al. 2008 recommendations of the International AIDS Society-USA panel. JAMA 2008;300:555-70.

4. Panel on Antiretroviral Guidelines for Adults and Adolescents. Guidelines for the use of antiretroviral agents in HIV-1-infected adults and adolescents. Department of Health and Human Services. December, 2009:1-161. < http://www.aidsinfo.nih.gov/ContentFiles/ AdultandAdolescentGL.pdf> (Accessed December 2, 2009).

5. Rouleau D, Fortin C, Trottier, et al; for the Comité consultatif sur la prise en charge clinique des personnes vivant avec le VIH. Antiretroviral Therapy for Adults Infected with HIV: Guidelines for Health Care Professionals from the Quebec HIV Care Committee.

Can J Infect Dis Med Microbiol 2010. (In press)

6. Kitahata MM, Gange SJ, Abraham AG, et al. Effect of early versus deferred antiretroviral therapy for HIV on survival. N Engl J Med 2009;360:1815-26.

7. Sax PE, Baden LR. When to start antiretroviral therapy - ready when you are? N Engl J Med 2009;360:1897-9.

8. When To Start Consortium. Timing of initiation of antiretroviral therapy in AIDS-free HIV-1-infected patients: A collaborative analysis of 18 HIV cohort studies. Lancet 2009;373:1352-63.

9. Strategies for Management of Antiretroviral Therapy (SMART) Study Group. Major clinical outcomes in antiretroviral therapy (ART) - naive participants and in those not receiving ART at baseline in the SMART study. J Infect Dis 2008;197:1133-44.

10. Hughes MD, Ribaudo HR. The search for data on when to start treatment for HIV infection. J Infect Dis 2008;197:1084-6.

11. Severe P, Pape J, Fitzgerald DW. A randomized clinical trial of early versus standard antiretroviral therapy for HIV-infected patients with a CD4 T cell count of $200-350$ cells/ml (CIPRAHT001). The 49th Interscience Conference on Antimicrobial Agents and Chemotherapy, San Francisco, September 12-15, 2009.

12. Rodriguez B, Sethi AK, Cheruvu VK, et al. Predictive value of plasma HIV RNA level on rate of CD4 T-cell decline in untreated HIV infection. JAMA 2006;296:1498-506.

13. Rodger AJ, Fox Z, Lundgren JD, et al. Activation and coagulation biomarkers are independent predictors of the development of opportunistic disease in patients with HIV infection. J Infect Dis 2009;200:973-83.

14. Neuhaus J, Jacobs D. Markers of inflammation, coagulation, and renal function in HIV-infected adults in the Strategies for Management of ART Study and in 2 large population-based studies, Coronary Artery Risk Development in Young Adults and Multi-Ethnic Study of pill burden and the adverse events they are willing to tolerate. Fixed-dose regimens have been able to successfully reduce the pill burden faced by the HIV-infected patient seeking treatment.

The success of ART in prolonging the survival of patients infected with HIV has raised a new series of clinical challenges because diabetes, heart disease and hypertension, among others, were not problems that HIV/AIDS patients had to concern themselves with. Presently, however, the selection of initial ART regimens must take into account that they will be given for an extended period of time, during which the patient will develop concomitant conditions. Without randomized clinical trials to support all of these decisions, more pressure is placed on the treating physician.

FINANCIAL SUPPORT: Financial assistance for the development of this manuscript was provided in the form of an unrestricted educational grant from Bristol-Myers Squibb Canada. The sponsor was not involved in any aspect of the development, literature interpretation, content or any other aspect of the manuscript. Authors were provided with compensation for travel and for participation in conference calls and advisory board meetings.

Atherosclerosis. The 16th Conference on Retroviruses and Opportunistic Infections (CROI), Montreal, February 8-11, 2009.

15. Bild DE, Bluemke DA, Burke GL, et al. Multi-Ethnic Study of Atherosclerosis: Objectives and design. Am J Epidemiol 2002;156:871-81.

16. Freidman GD, Cutter GR, Donahue RP, et al. CARDIA: Study design, recruitment, and some characterisitics ogf the examined subjects. J Clin Epidemiol 1988;41:1105-16.

17. Grant P, Komarow L, Sereti I, et al. Risk factor analyses for immune reconstitution inflammatory syndrome and mortality during a randomized trial of early versus deferred ART in the setting of acute opportunistic infections: ACTG A5164. The 16th Conference on Retroviruses and Opportunistic Infections (CROI), Montreal, February 8-11, 2009.

18. Justice A; for the Veterans Aging Cohort Study (VACS) Project Team. Non-HIV biomarkers independently predict mortality and are associated with HIV markers. The 16th Conference on Retroviruses and Opportunistic Infections (CROI), Montreal, February 8-11, 2009

19. Sabin CA, d'Arminio Monforte A, Friis-Moller N, et al; Data Collection On Adverse Events Of Anti-HIV Drugs Study Group. Changes over time in risk factors for cardiovascular disease and use of lipid-lowering drugs in HIV-infected individuals and impact on myocardial infarction. Clin Infect Dis 2008;46:1101-10.

20. Smith C. D:A:D Study Group. Association between modifiable and non-modifiable risk factors and specific causes of death in the HAART era: The Data Collection on Adverse Events of Anti-HIV Drugs Study. The 16th Conference on Retroviruses and Opportunistic Infections (CROI), Montreal, February 8-11, 2009.

21. Quinn TC. Viral load, circumcision and heterosexual transmission. Hopkins HIV Rep 2000;12:1,5,11.

22. Sperling RS, Shapiro DE, Coombs RW, et al. Maternal viral load, zidovudine treatment, and the risk of transmission of human immunodeficiency virus type 1 from mother to infant. Pediatric AIDS Clinical Trials Group Protocol 076 Study Group. N Engl J Med 1996;335:1621-9.

23. Dickover RE, Garratty EM, Herman SA, et al. Identification of levels of maternal HIV-1 RNA associated with risk of perinatal transmission. Effect of maternal zidovudine treatment on viral load. JAMA 1996;275:599-605.

24. Thea DM, Steketee RW, Pliner V, et al. The effect of maternal viral load on the risk of perinatal transmission of HIV-1. New York City Perinatal HIV Transmission Collaborative Study Group. AIDS 1997;11:437-44.

25. Garcia PM, Kalish LA, Pitt J, et al; Women and Infants Transmission Study Group. Maternal levels of plasma human immunodeficiency virus type 1 RNA and the risk of perinatal transmission. N Engl J Med 1999;341:394-402.

26. Attia S, Egger M, Müller M, Zwahlen M, Low N. Sexual transmission of HIV according to viral load and antiretroviral therapy: Systemic review and meta-analysis. AIDS 2009;23:1397-404. 
27. Sheth PM, Kovacs C, Kemal KS, et al; Mucosal Immunology Group. Persistent HIV RNA shedding in semen despite effective antiretroviral therapy. AIDS 2009;23:2050-4.

28. Lorello G, la Porte C, Pilon R, Zhang G, Karnauchow T, MacPherson P. Discordance in HIV-1 viral loads and antiretroviral drug concentrations comparing semen and blood plasma. HIV Med 2009; 10:548-54.

29. Lafeuillade A, Solas C, Halfon P, Chadapaud S, Hittinger G, Lacarelle B. Differences in the detection of three HIV-1 protease inhibitors in non-blood compartments: Clinical correlations. HIV Clin Trials 2002;3:27-35.

30. Lafeuillade A, Solas C, Chadapaud S, Hittinger G, Poggi C, Lacarelle B. HIV-1 RNA levels, resistance, and drug diffusion in semen versus blood in patients receiving a lopinavir-containing regimen. J Acquir Immune Defic Syndr 2003;32:462-4.

31. Eron JJ Jr, Smeaton LM, Fiscus SA, et al. The effects of protease inhibitor therapy on human immunodeficiency virus type 1 levels in semen (AIDS clinical trials group protocol 850). J Infect Dis 2000;181:1622-8.

32. Bujan L, Daudin M, Matsuda T, et al. Factors of intermittent HIV-1 excretion in semen and efficiency of sperm processing in obtaining spermatozoa without HIV-1 genomes. AIDS 2004;18:757-66.

33. Leruez-Ville M, Dulioust E, Costabliola D, et al. Decrease in HIV-1 seminal shedding in men receiving highly active antiretroviral therapy: An 18-month longitudinal study (ANRS EP012). AIDS 2002;16:486-8.

34. Fiore JR, Suligoi B, Saracino A, et al. Correlates of HIV-1 shedding in cervicovaginal secretions and effects of antiretroviral therapies. AIDS 2003;17:2169-76.

35. Brenner BG, Roger M, Routy JP, et al. High rates of forward transmission events after acute/early HIV-1 infection. J Infect Dis 2007;195:951-9.

36. Fisher M, Sudarshi D, Brown A, et al. HIV transmission among men who have sex with men: Association with ART, infection stage, viremia, and sexually transmitted diseases, a longitudinal phylogenetic study. The 16th Conference on Retroviruses and Opportunistic Infections (CROI), Montreal, February 8-11, 2009.

37. Balfour L, Kowal J, Silverman A, et al. A randomized controlled psycho-education intervention trial: Improving psychological readiness for successful HIV medication adherence and reducing depression before initiating HAART. AIDS Care 2006;18:830-8.

38. Balfour L, Tasca GA, Kowal J, et al. Development and validation of the HIV Medication Readiness Scale. Assessment 2007;14:408-16.

39. Public Health Agency of Canada. HIV-1 Strain and Primary Drug Resistance in Canada Surveillance Report to June 30, 2002. $<$ http://www.phac-aspc.gc.ca/publicat/hiv1-vih1-02/index-eng. php\#toc $>$ (Accessed on February 11, 2010).

40. van Leth F, Phanuphak P, Ruxrungtham K, et al. Comparison of first-line antiretroviral therapy with regimens including nevirapine, efavirenz, or both drugs, plus stavudine and lamivudine: A randomised open-label trial, the 2NN Study. Lancet 2004;363:1253-63.

41. Antiretroviral Pregnancy Registry Steering Committee. Antiretroviral Pregnancy Registry International Interim Report for 1 January 1989 through 31 July 2009. Wilmington, NC: Registry Coordinating Center, 2009. <www.APRegistry.com> (Accessed on July 14, 2009).

42. Lundgren J, Reiss P, Worm S, et al. Risk of myocardial infarction with exposure to specific ARV from the PI, NNRTI, and NRTI drug classes: The D:A:D Study. The 16th Conference on Retroviruses and Opportunistic Infections (CROI), Montreal, February 8-11, 2009.

43. Molina JM, Andrade-Villanueva J, Echevarria J, et al. Once-daily atazanavir/ritonavir versus twice-daily lopinavir/ritonavir, each in combination with tenofovir and emtricitabine, for management of antiretroviral-naive HIV-1-infected patients: 48 week efficacy and safety results of the CASTLE study. Lancet 2008;372:646-55.

44. Molina J-M, Andrade-Villanueva J, Echevarria J, et al. Atazanavir/ritonavir vs lopinavir/ritonavir in antiretroviral-naïve HIV-1-infected patients: CASTLE 96 week efficacy and safety. The 48th Annual ICAAC/IDSA 46th Annual Meeting: A Joint Meeting of the American Society for Microbiology and the Infectious Diseases Society of America, Washington DC, October 25-28, 2008.

45. Mills AM, Nelson M, Jayaweera D, et al. Once-daily darunavir/ ritonavir vs. lopinavir/ritonavir in treatment-naive, HIV-1-infected patients: 96-week analysis. AIDS 2009;23:1679-88.

46. Nelson M, Yeni P, Sension M, et al. Factors affecting virologic response to darunavir/ritonavir and lopinavir/ritonavir in treatment-naïve HIV-1-infected patients in ARTEMIS at 96 weeks. The 16th Conference on Retroviruses and Opportunistic Infections (CROI), Montreal, February 8-11, 2009.

47. Eron J Jr, Yeni P, Gathe J Jr, et al. The KLEAN study of fosamprenavir-ritonavir versus lopinavir-ritonavir, each in combination with abacavir-lamivudine, for initial treatment of HIV infection over 48 weeks: A randomised non-inferiority trial. Lancet 2006;368:476-82.

48. Pulido F, Estrada V, Baril JG, et al. Long-term efficacy and safety of fosamprenavir plus ritonavir versus lopinavir/ritonavir in combination with abacavir/lamivudine over 144 weeks. HIV Clin Trials 2009;10:76-87.

49. Walmsley S Avihingsanon A, Slim J, et al. Gemini: A non-inferiority study of saquinavir/ritonavir versus lopinavir/ritonavir as initial HIV-1 therapy in adults. J Acquir Immune Defic Syndr 2009;50:367-74.

50. Smith KY, Weinberg WG, Dejesus E, et al. Fosamprenavir or atazanavir once daily boosted with ritonavir $100 \mathrm{mg}$, plus tenofovir/emtricitabine, for the initial treatment of HIV infection: 48-week results of ALERT. AIDS Res Ther 2008;5:5.

51. Riddler SA, Haubrich R, DiRienzo AG, et al. Class-sparing regimens for initial treatment of HIV-1 infection. N Engl J Med 2008;358:2095-106.

52. Haubrich RH, Riddler SA, DiRienzo AG, et al. Drug resistance at virologic failure in a randomized Phase III trial (ACTG 5142). Antiviral Therapy 2007;12:66.

53. Soriano V, Köppe S, Mingrone H, et al. Prospective comparison of nevirapine and atazanavir/ritonavir both combined with tenofovir DF/emtricitabine in treatment-naïve HIV-1 infected patients: ArTEN study week 48 results. The 5 th International AIDS Society Conference on HIV: Pathogenesis, Treatment and Prevention. Cape Town, July 19-22, 2009.

54. Cooper DA, et al; Altair Study Group. Safety and efficacy of three different combination antiretroviral regimens as initial therapy for HIV infection: Week 48 data from a randomised, open-label study. The 5th International AIDS Society Conference on HIV: Pathogenesis, Treatment and Prevention. Cape Town, July 19-22, 2009.

55. Daar E, Tierney C, Fisch M, et al. ACTG 5202: Final results of $\mathrm{ABC} / 3 \mathrm{TC}$ or TDF/FTC with either EFV or ATV/r in treatment-naive HIV-infected patients. The 17th Conference on Retroviruses and Opportunistic Infections (CROI), San Francisco, February 16-19, 2010.

56. Lennox JL DeJesus E, Lazzarin A, et al. Safety and efficacy of raltegravir-based versus efavirenz-based combination therapy in treatment-naive patients with HIV-1 infection: A multicentre, double-blind randomised controlled trial. Lancet 2009;374:796-806.

57. Lennox J, DeJesus E, Lazzarin A, et al. Subgroup Analyses from STARTMRK, a phase III study of raltegravir (RAL)-based vs efavirenz (EFV)-based combination therapy in treatment-naïve HIV-infected patients. The 16th Conference on Retroviruses and Opportunistic Infections (CROI), Montreal, February 8-11, 2009.

58. Markowitz M, Nguyen BY, Gotuzzo E, et al. Sustained antiretroviral effect of raltegravir after 96 weeks of combination therapy in treatment-naive patients with HIV-1 infection. J Acquir Immune Defic Syndr 2009;52:350-6.

59. Sax PE, Tierney C, Collier AC, et al. Abacavir-lamivudine versus tenofovir-emtricitabine for initial HIV-1 therapy. N Engl J Med 2009;361:2230-40.

60. Stellbrink HJ, Moyle G, Orkin C, et al. Assessment of safety and efficacy of abacavir/lamivudine and tenofovir/emtricitabine in treatment-naive HIV-1 infected subjects. ASSERT: 48-week result. The 12th European AIDS Conference. Cologne, November 11-14, 2009.

61. Smith KY, Fine D, Patel P, et al. Efficacy and safety of abacavir/ lamivudine compared to tenofovir/emtricitabine in combination with once-daily lopinavir/ritonavir through 48 weeks in the HEAT Study. The 15th Conference on Retroviruses and Opportunistic Infections (CROI), Boston, February 3-8, 2008.

62. Smith KY, Patel P, Fine D, et al. Randomized, double-blind, placebo-matched, multicenter trial of abacavir/lamivudine or tenofovir/emtricitabine with lopinavir/ritonavir for initial HIV treatment. AIDS 2009;23:1547-56.

63. Haubrich RH, Riddler SA, DiRienzo AG, et al. Metabolic outcomes in a randomized trial of nucleoside, nonnucleoside and protease inhibitor-sparing regimens for initial HIV treatment. AIDS 2009;23:1109-18.

64. Aslangul E, Assoumou L, Bittar R, et al. Rosuvastatin versus pravastatin in dyslipidemic HIV-1-infected patients receiving protease inhibitors: A randomized trial. AIDS 2010;24:77-83.

65. Cannon CP, Braunwald E, McCabe $\mathrm{CH}$, et al. Intensive versus moderate lipid lowering with statins after acute coronary syndromes. N Engl J Med 2004;350:1495-504. 
66. Silverberg MJ, Leyden W, Hurley L, et al. Response to newly prescribed lipid-lowering therapy in patients with and without HIV infection. Ann Intern Med 2009;150:301-13.

67. Bozzette SA, Ake CF, Tam HK, et al. Long-term survival and serious cardiovascular events in HIV-infected patients treated with highly active antiretroviral therapy. J Acquir Immune Defic Syndr 2008; $47: 338-41$

68. Friis-Møller N, Reiss P, Sabin CA, et al; D:A:D Study Group. Class of antiretroviral drugs and the risk of myocardial infarction. N Engl J Med 2007;356:1723-35.

69. Lang S, Mary-Krause M, Cotte L, et al. Impact of specific NRTI and PI exposure on the risk of myocardial infarction: A case-control study nested within FHDH ANRS CO4. The 16th Conference on Retroviruses and Opportunistic Infections (CROI), Montreal, February 8-11, 2009.

70. Durand M, Sheehy O, Baril J-G, Lelorier J, Tremblay C; GRUCHUM Research Center. Relation between use of nucleoside reverse transcriptase inhibitors (NRTI) and risk of myocardial infarction (MI): A nested case control study using Quebec's public health insurance database (QPHID). The 5th International AIDS Society Conference on HIV: Pathogenesis, Treatment and Prevention. Cape Town, July 19-22, 2009.

71. Sabin CA, Worm SW, Weber R; D:A:D Study Group. Use of nucleoside reverse transcriptase inhibitors and risk of myocardial infarction in HIV-infected patients enrolled in the D:A:D study: A multi-cohort collaboration. Lancet 2008;371:1417-26.

72. SMART/INSIGHT, D:A:D Study Groups. Use of nucleoside reverse transcriptase inhibitors and risk of myocardial infarction in HIV-infected patients. AIDS 2008;22:F17-24.

73. Bedimo R, Westfall A, Drechsler H, Tebas P. Abacavir use and risk of acute myocardial infarction and cerebrovascular disease in the HAART era. The 5th International AIDS Society Conference on HIV: Pathogenesis, Treatment and Prevention. Cape Town, July 19-22, 2009.

74. Brothers CH, Hernandez JE, Cutrell AG, et al. Risk of myocardial infarction and abacavir therapy: No increased risk across 52 GlaxoSmithKline-sponsored clinical trials in adult subjects. J Acquir Immune Defic Syndr 2009;51:20-8.

75. Benson C, Ribaudo H, Zheng E, et al. No association of abacavir use with risk of myocardial infarction or severe cardiovascular disease events: Results from ACTG A5001. The 16th Conference on Retroviruses and Opportunistic Infections (CROI), Montreal, February 8-11, 2009.

76. Shuter J. Forgiveness of non-adherence to HIV-1 antiretroviral therapy. J Antimicrob Chemother 2008;61:769-73.

77. Bangberg DR. Less than $95 \%$ adherence to nonnucleoside reversetranscriptase inhibitor therapy can lead to viral suppression. Clin Infect Dis 2006;43:939-41.

78. Paterson DL, Swindells S, Mohr J, et al. Adherence to protease inhibitor therapy and outcomes in patients with HIV infection. Ann Intern Med 2000;133:21-30.

79. Shuter J, Sarlo JA, Kanmaz, et al. HIV-infected patients receiving lopinavir/ritonavir-based antiretroviral therapy acheive high rates of virologic suppression despite adherence rates below $95 \%$. J AIDS 2007;45:4-8.

80. Tam LW, Chui CK, Brumme CJ, et al. The relationship between resistance and adherence in drug-naive individuals initiating HAART is specific to individual drug classes. J Acquir Immune Defic Syndr 2008;49:266-71.

81. Rosenblum M, Deeks SG, van der Laan MJ, Bangsberg DR. The risk of virologic failure decreases with duration of continuous viral suppression, for adherence levels above $50 \%$. The 16th Conference on Retroviruses and Opportunistic Infections (CROI), Montreal, February 8-11, 2009.

82. Protopopescu C, Raffi F, Roux P, et al. Factors associated with non-adherence to long-term highly active antiretroviral therapy: A 10 -year follow-up analysis with correction for the bias induced by missing data. J Antimicrob Chemother 2009;64:599-606.

83. Martin M, Del Cacho E, Codina C, et al. Relationship between adherence level, type of the antiretroviral regimen, and plasma HIV type 1 RNA viral load: A prospective cohort study. AIDS Res Hum Retroviruses 2008;24:1263-8.

84. Cohen CJ, Colson AE, Sheble-Hall AG, McLaughlin KA, Morse GD. Pilot study of a novel short-cycle antiretroviral treatment interruption strategy: 48-week results of the five-days-on, two-days-off (FOTO) study. HIV Clin Trials 2007;8:19-23.

85. Cohen C, Colson A, Pierone G, et al. The FOTO study: The 48-week extension to assess durability of the strategy of taking efavirenz, tenofovir and emtricitabine Five days On, Two days Off (FOTO) each week in virologically suppressed patients. The 5th International AIDS Society Conference on HIV: Pathogenesis, Treatment and Prevention. Cape Town, July 19-22, 2009.

86. Wood E, Hogg RS, Yip B, Harrigan PR, O'Shaughnessy MV, Montaner JS. Effect of medication adherence on survival of HIV-infected adults who start highly active antiretroviral therapy when the CD4 cell count is 0.200 to $0.350 \times 10$ (9) cells/L. Ann Intern Med 2003;139:810-16.

87. Patel P, Hanson DL, Sullivan PS, et al. Incidence of types of cancer among HIV-infected persons compared with the general population in the United States, 1992-2003. Ann Intern Med 2008;148:728-36.

88. Guiguet M, Boué F, Cadranel J, Lang JM, Rosenthal E, Costagliola D. Effect of immunodeficiency, HIV viral load, and antiretroviral therapy on the risk of individual malignancies (FHDH-ANRS CO4): A prospective cohort study. Lancet Oncol 2009;10:1152-9.

89. Kalayjian RC, Franceschini N, Gupta SK, et al. Suppression of HIV-1 replication by antiretroviral therapy improves renal function in persons with low CD4 cell counts and chronic kidney disease. AIDS 2008;22:481-7.

90. Kirk O, Mocroft A, Reiss P, et al. Chronic kidney disease and exposure to ART in a large cohort with long-term follow-up: The EuroSIDA Study. The 17th Conference on Retroviruses and Opportunistic Infections (CROI), San Francisco, February 16-19, 2010.

91. Shafran SD. Early initiation of antiretroviral therapy: The current best way to reduce liver-related deaths in HIV/hepatitis C virus co-infected patients. J Acquir Immune Defic Syndr 2007;44:551-6.

92. d'Arminio Monforte A, Cozzi-Lepri A, Castagna A, et al. Risk of developing specific AIDS-defining illnesses in patients co-infected with HIV and hepatitis $C$ virus with or without liver cirrhosis. Clin Infect Dis 2009;49:612-22.

93. Alvarez D, Dieterich DT, Brau N, Moorehead L, Ball L, Sulkowski MS. Zidovudine use but not weight-based ribavirin dosing impacts anaemia during HCV treatment in HIV-infected persons. J Viral Hepat 2006;13:683-9.

94. Centers for Disease Control and Prevention. Guidelines for prevention and treatment of opportunistic infections in HIV-infected adults and adolescents. MMWR 2009;58(No. RR-4):84-91.

95. Fleischer R, Boxwell D, Sherman KE. Nucleoside analogues and mitochondrial toxicity. Clin Infect Dis 2004;38:e79-80.

96. Mauss S, Valenti W, DePamphilis J, et al. Risk factors for hepatic decompensation in patients with HIV/HCV coinfection and liver cirrhosis during interferon-based therapy. AIDS 2004;18:F21-5.

97. Bani-Sadr F, Denoeud L, Morand P, et al. Early virologic failure in HIV-coinfected hepatitis $C$ patients treated with the peginterferonribavirin combination: Does abacavir play a role? J Acquir Immune Defic Syndr 2007;45:123-5.

98. Vispo E, Barreiro P, Pineda JA, et al. Low response to pegylated interferon plus ribavirin in HIV-infected patients with chronic hepatitis C treated with abacavir. Antivir Ther 2008;13:429-37.

99. Mira JA, López-Cortés LF, Barreiro P, et al. Efficacy of pegylated interferon plus ribavirin treatment in HIV/hepatitis $\mathrm{C}$ virus co-infected patients receiving abacavir plus lamivudine or tenofovir plus either lamivudine or emtricitabine as nucleoside analogue backbone. J Antimicrob Chemother 2008;62:1365-73.

100. Laufer N, Laguno M, Perez I, et al. Abacavir does not influence the rate of virological response in HIV-HCV-coinfected patients treated with pegylated interferon and weight-adjusted ribavirin. Antivir Ther 2008;13:953-7.

101. Moreno A, Quereda C, Muriel A, et al. Does the choice of NRTI have a significant influence on the outcome of peg-IFN plus ribavirin among HIV/HCV-co-infected patients? The 15th Conference on Retroviruses and Opportunistic Infections (CROI), Boston, February 3-8, 2008.

102. Podzamczer D, Ferrer E, Sanchez P, et al. ABCDE (Abcavir vs. d4T [stavudine] plus efavirenz) Study Team. Less lipoatrophy and better lipid profile with abvavir as compared to stavudine: 96-week results of a randomized study. J Acquir Immune Defic Syndr 2007;44:139-47. 


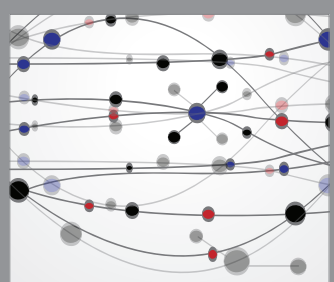

The Scientific World Journal
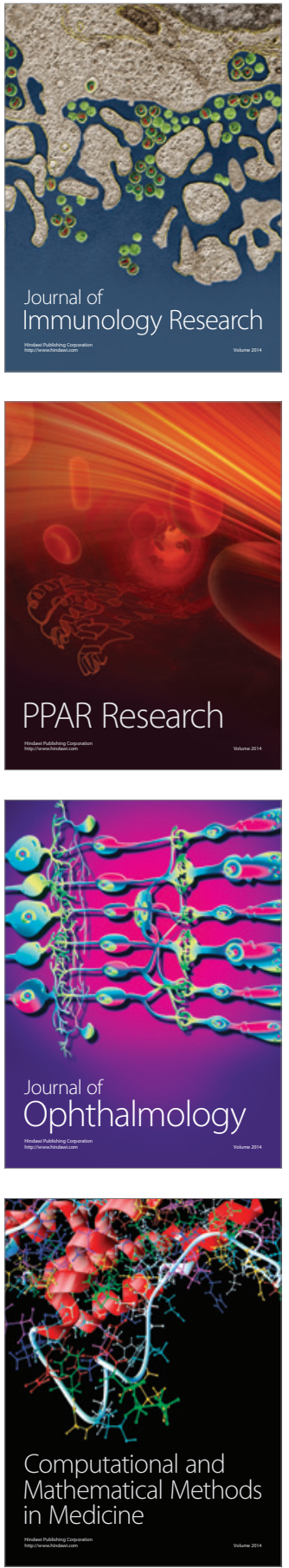

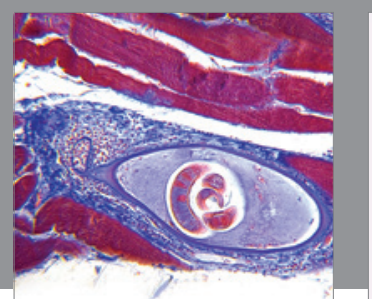

Gastroenterology Research and Practice

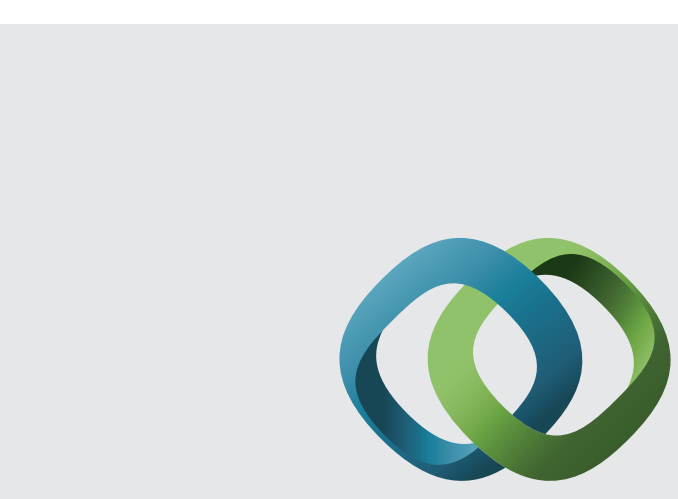

\section{Hindawi}

Submit your manuscripts at

http://www.hindawi.com
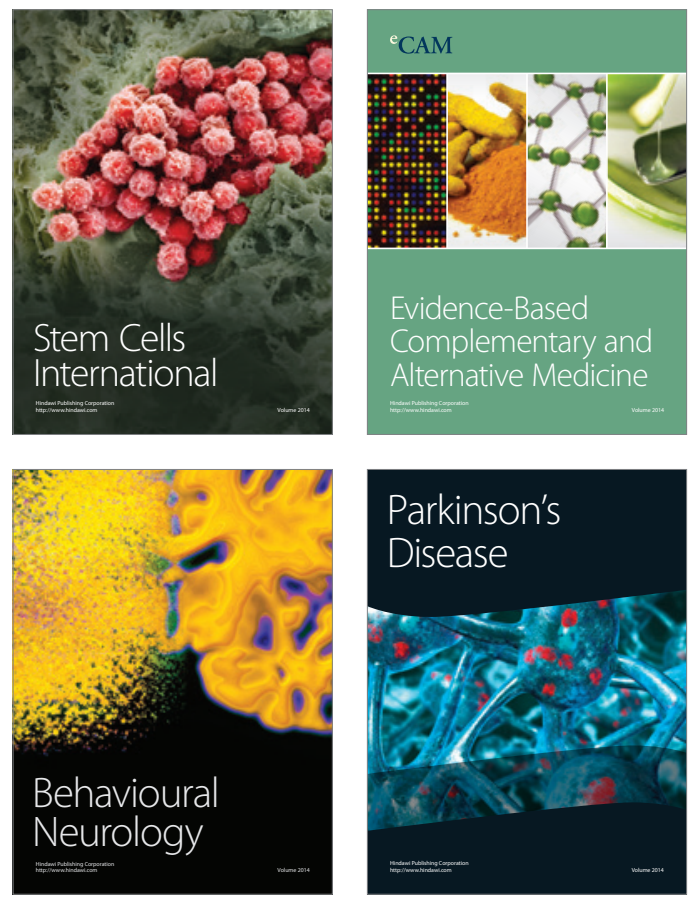
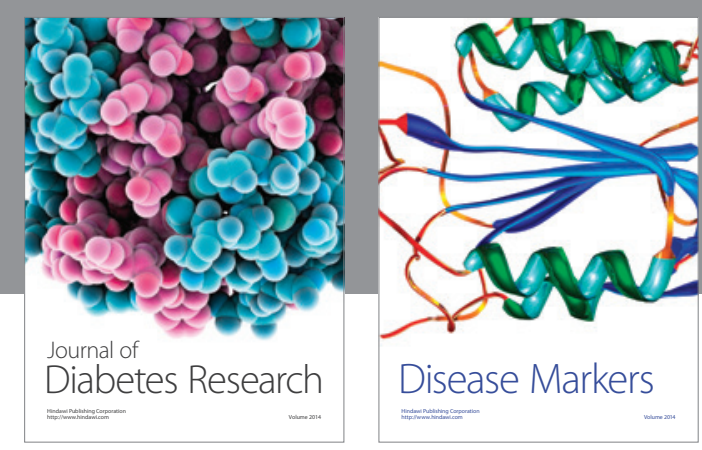

Disease Markers
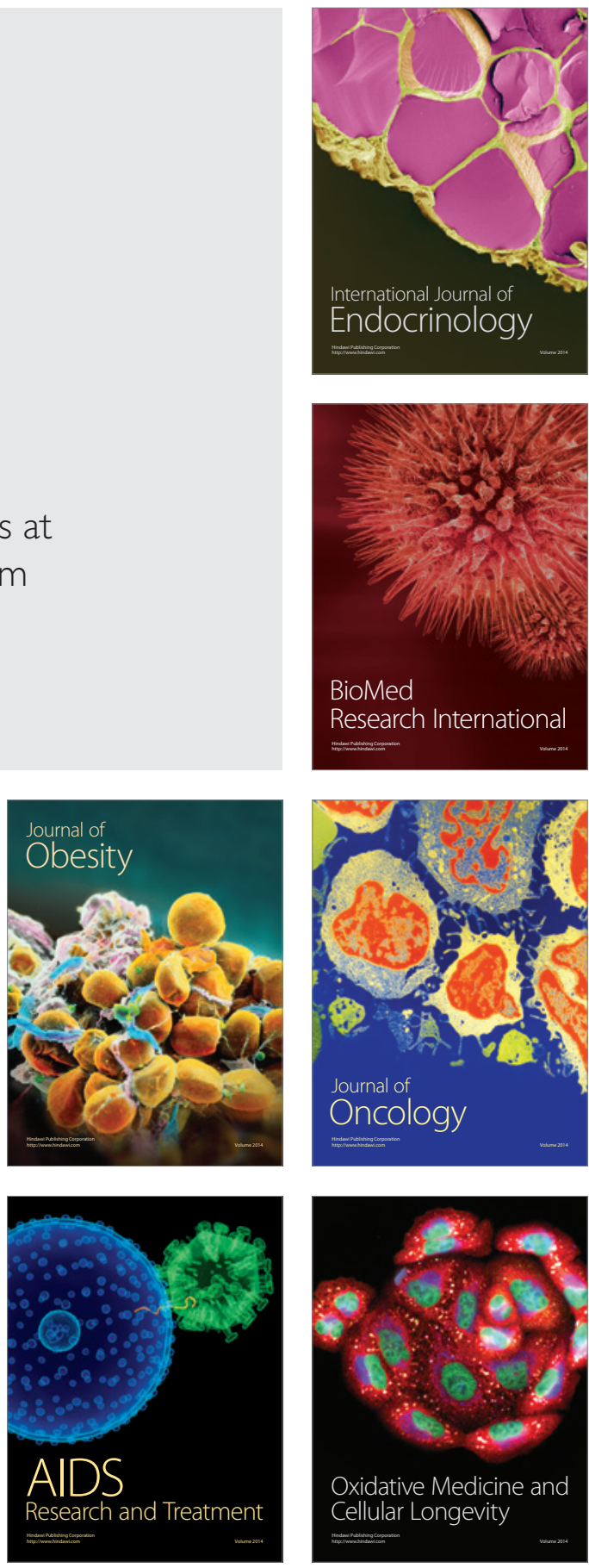